Roberta Thiery de Godoy Arashiro

\title{
Avaliação do perfil microbiológico e dos fatores de risco relacionados ao desenvolvimento de bolsites em pacientes com bolsa ileal por retocolite ulcerativa
}

Dissertação apresentada à Faculdade de Medicina da Universidade de São Paulo para obtenção do título de Mestre em Ciências

Programa de Cirurgia do Aparelho Digestivo

Orientadora: Profa. Dra. Magaly Gemio Teixeira 
Dados Internacionais de Catalogação na Publicação (CIP)

Preparada pela Biblioteca da

Faculdade de Medicina da Universidade de São Paulo

Creprodução autorizada pelo autor

Arashiro, Roberta Thiery de Godoy

Avaliação do perfil microbiológico e dos fatores de risco relacionados ao desenvolvimento de bolsites em pacientes com bolsa ileal por retocolite ulcerativa / Roberta Thiery de Godoy Arashiro. --- São Paulo, 2012.

Dissertação(mestrado)--Faculdade de Medicina da Universidade de São Paulo. Programa de Cirurgia do Aparelho Digestivo.

Orientadora: Magaly Gemio Teixeira.

Descritores: 1.Proctocolite 2.Pouchite 3.Proctolectomia restauradora 3.Microbiologia 4.Histologia 5.Fatores de risco

USP/FM/DBD-037/12 
Esta dissertação está de acordo com as seguintes normas, em vigor no momento desta publicação:

Referências: adaptado de International Committee of Medical Journals Editors (Vancouver).

Universidade de São Paulo. Faculdade de Medicina. Divisão de Biblioteca e Documentação. Guia de apresentação de dissertações, teses e monografias. Elaborado por Anneliese Carneiro da Cunha, Maria Julia de A. L. Freddi, Maria F. Crestana, Marinalva de Souza Aragão, Suely Campos Cardoso, Valéria Vilhena. 3a ed. São Paulo: Divisão de Biblioteca e Documentação; 2011.

Abreviaturas dos títulos dos periódicos de acordo com List of Journals Indexed in Index Medicus. 


\section{DEDICATÓRIA}


Este trabalho é dedicado a meus pais, Masahiro Arashiro e Dalva Godoy Arashiro, por todos os valores aprendidos durante minha vida, de ética, disciplina, perseverança e profissionalismo. Mas, principalmente, por todo o amor e confiança que sempre depositaram em mim, que moldaram a pessoa em que me transformei e cujos ensinamentos me guiam por toda a vida. Meu profundo amor e agradecimento.

Dedico também a meu esposo, Carlos Rodolfo Figueiredo Braga, que me faz crescer dia a dia com nossa troca de experiências, por todo o amor, paciência e incentivo dedicados que me fazem seguir em frente nos momentos mais difíceis e por compartilhar comigo nossas conquistas e também nossos momentos mais felizes. Saiba que você é fundamental em minha vida e que é com felicidade imensurável que compartilho com você a chegada de nossa filha. 
AGRADECIMENTOS 
À Professora Doutora Magaly Gemio Teixeira por todo o carinho, disposição, experiência e apoio dedicados durante todo este período. Além desta etapa concluída, nosso convívio foi suficiente para admirá-la ainda mais, não apenas no âmbito profissional. Levarei por toda a vida também os princípios de caráter e ensinamentos aprendidos. Para a senhora, todo o meu carinho e reconhecimento.

À amiga Celina Sobreira pelo enorme incentivo, apoio em todos os aspectos, e por me ajudar a enxergar o mundo de uma nova maneira. Sem sua participação, a realização deste trabalho com certeza não seria possível.

Ao meu mestre e amigo, Professor Doutor Alexandre Bakonyi Neto, por ter sido sempre um grande incentivador, pelos ensinamentos e pela confiança desde o início de minha vida profissional.

Ao Professor Doutor Sérgio Carlos Nahas pelo incentivo e interesse neste trabalho.

Ao Professor Doutor Ivan Cecconello e demais integrantes do grupo de Cirurgia do Cólon e Reto da FMUSP pelo apoio.

Aos Professores Doutores Luiz Augusto Carneiro D’Albuquerque e José Jukemura pela acolhida e incentivo. 
À amiga Alina Quintanilha por toda a disposição, interesse e grande auxílio em minha pesquisa.

Aos colegas patologistas, Professora Doutora Viviane Rawet, Henrique Moura de Paula e Adriano Zanon Silva pela paciência, disposição e pela avaliação histopatológica realizada, fundamentais para a conclusão deste trabalho.

Ao microbiologista Professor Manoel Santos por toda a atenção e criteriosa análise microbiológica, de suma importância para o estudo.

Aos amigos e funcionários do Ambulatório de Doenças Inflamatórias Intestinais, por todo o carinho e incentivo durante este período.

Aos funcionários da secretaria e biblioteca do Departamento de Cirurgia do Aparelho de Cirurgia Digestiva pela paciência, simpatia e disposição em me ajudar em todos os momentos.

Aos estaticistas Demerson Polli e Ítalo pelo apoio e pela análise estatística, de suma importância para este trabalho.

À bibliotecária Marinalva de Souza Aragão por toda a paciência e disposição, fundamentais para a conclusão deste estudo. 
“Temos de nos tornar a mudança que queremos ver no mundo" Mahatma Gandhi 


\title{
SUMÁRIO
}

\author{
RESUMO
}

ABSTRACT

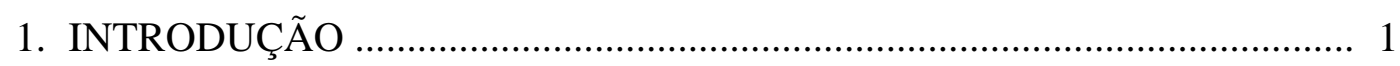

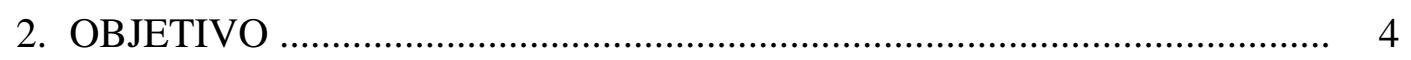

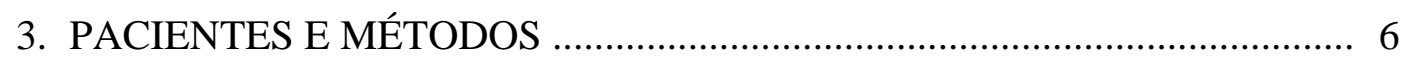

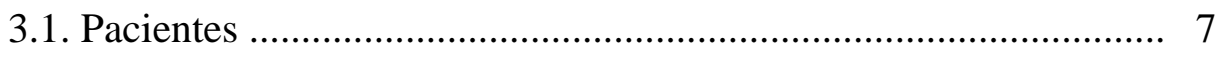

3.2. Métodos ........................................................................... 10

3.2.1. Avaliação endoscópica da bolsa ileal .............................10

3.2.2. Estudo microbiológico .............................................. 10

3.2.3. Estudo histopatológico ............................................. 12

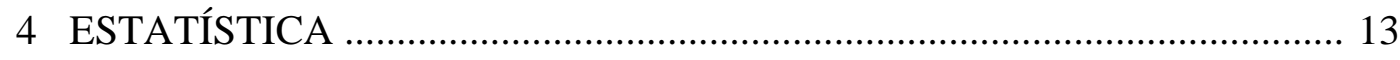

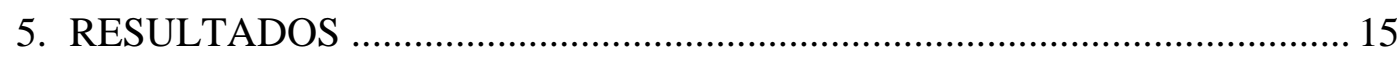

5.1. Análise microbiológica dos produtos de biópsias ........................ 16

5.2. Análise microbiológica das amostras fecais ............................... 20

5.3. Avaliação histopatológica dos produtos de biópsias ..................... 25

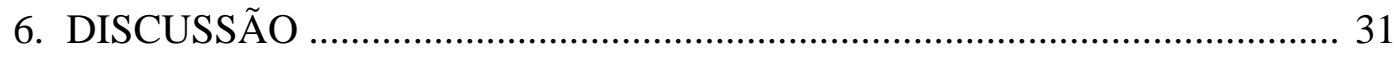

6.1. Análise microbiológica ......................................................... 33

6.2. Análise histopatológica .......................................................... 42

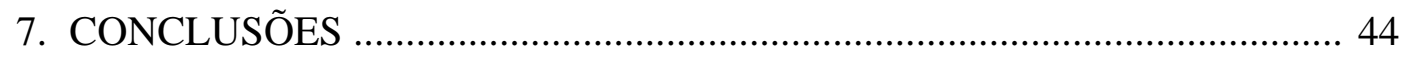

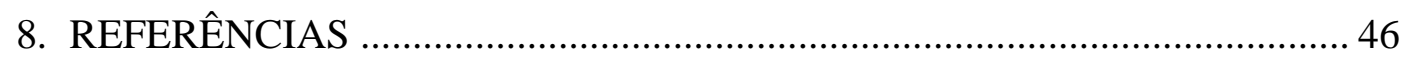

\section{APÊNDICES}




\section{RESUMO}

Arashiro RTG. Avaliação do Perfil Microbiológico e dos Fatores de Risco Relacionados ao Desenvolvimento de Bolsites em Pacientes com Bolsa Ileal por Retocolite Ulcerativa [dissertação]. São Paulo: Faculdade de Medicina, Universidade de São Paulo; 2012. 57p.

INTRODUÇÃO: A bolsite tem sido descrita como a complicação mais comum após a realização de bolsa ileal por retocolite ulcerativa. A etiologia da bolsite não está clara, mas sua resolução ocasional com metronidazol e/ou ciprofloxacina sugere que a estase fecal e a superproliferação bacteriana possam estar envolvidas na sua patogênese. Poucos estudos analisaram culturas microbianas de amostras teciduais. Além disso, várias alterações na morfologia da mucosa são vistas após a construção das bolsas ileais, como inflamação aguda e crônica com atrofia vilosa, hiperplasia de criptas, metaplasia colônica e displasias. OBJETIVO: O objetivo deste estudo é caracterizar a microflora das bolsas ileais de pacientes operados por RCU com e sem bolsites, além de caracterizar as alterações histopatológicas mais freqüentes nas bolsas ileais e correlacioná-las com possíveis fatores de risco para o desenvolvimento de bolsites. MÉTODOS: Quarenta e um pacientes foram envolvidos no estudo, divididos em três grupos: o grupo sem bolsite (NB) não apresentava inflamação da bolsa ileal ao momento da avaliação ( $\mathrm{n}=20 ; 12$ mulheres; média de idade, 47.5 anos); o grupo BNA apresentava bolsite e incluía pacientes sem uso de antibióticos ( $n=14$; 10 mulheres; média de idade, 47 anos) e o grupo BA incluía pacientes com bolsite fazendo uso de antibióticos ( $\mathrm{n}=7 ; 4$ mulheres; média de idade, 41 anos). Foi realizada avaliação endoscópica da bolsa ileal com coleta de fezes e amostras teciduais para análise microbiológica e histopatológica. RESULTADOS: Houve tendência a concentrações aumentadas de Bacteroides sp em pacientes com bolsites $(p=0,072)$. No entanto, concentrações significativamente mais elevadas foram observadas no grupo BA $(p=0,018)$ comparativamente ao grupo NB. A presença de anaeróbios estritos na flora associada à mucosa aumentou o risco para desenvolvimento de bolsites $(\mathrm{p}=0,048)$. Foram observadas concentrações significativamente elevadas de Propionibacterium $s p$ em pacientes com bolsites $(\mathrm{p}=0,009)$ e de Candida $s p(\mathrm{p}=0,043)$ e Fusobacterium $s p(\mathrm{p}=0,045)$ no grupo BA comparativamente ao grupo NB. A metaplasia colônica foi encontrada em 15 (36,6\%) dos 41 pacientes: 5 (25\%) do grupo NB, $8(57,1 \%)$ do grupo BNA e 2 $(28,6 \%)$ do grupo BA. No entanto, nenhuma correlação foi estabelecida entre sua presença e a ocorrência de bolsites $(\mathrm{p}=0,17)$. O grau de atrofia mucosa da bolsa ileal correlacionou-se com o tempo de seguimento pós-operatório $(p=0,055)$. CONCLUSÕES: Concentrações elevadas de Bacteroides sp na flora associada à mucosa parecem aumentar o risco de desenvolvimento de bolsites; ao mesmo tempo, há um aumento na probabilidade de sua ocorrência à medida em que aumenta a concentração de anaeróbios na bolsa ileal; O grau de atrofia da mucosa, a presença de metaplasia colônica, o grau de inflamação aguda ou crônica não parecem constituir fatores de risco para o desenvolvimento de bolsites; quanto maior o tempo de seguimento pós-operatório, maior o grau de atrofia da mucosa.

Descritores: 1.Proctocolite 2.Pouchite 3.Proctocolectomia Restauradora 4.Microbiologia 5.Histolologia 6.Fatores de risco 


\begin{abstract}
Arashiro RTG. Microbiological assessment and risk factors related to developing pouchitis in patients with Ileal Pouch- Anal Anastomosis by Ulcerative Colitis [dissertation]. São Paulo: Faculdade de Medicina, Universidade de São Paulo; 2012. 57p.
\end{abstract}

INTRODUCTION: Pouchitis has been described as the most common complication after ileal pouch-anal anastomosis for ulcerative colitis. The etiology of pouchitis is not clear, but its occasional resolution with metronidazole and/or ciprofloxacin suggests that fecal stasis and bacterial overgrowth may be involved in the disease process. Few studies have analyzed microbial cultures from tissue biopsy samples. Furthermore, many changes in mucosal morphology are seen after ileal pouch construction, like acute and chronic inflammation with villus atrophy, crypt hyperplasia, colonic metaplasia and dysplasia. AIM: The aim of this study is to characterize microflora of ileal pouches in patients with and without pouchitis and evaluate the most frequent histopatological changes in ileal pouches and correlate them with possible risk factors for the development of pouchitis. METHODS: Fortyone patients were enrolled in the study, divided into three groups: the no-pouchitis group (NB) had no pouchitis at the time of evaluation ( $n=20 ; 14$ females; mean age, 47.5 years), the pouchitis group (BNA) had pouchitis but included patients not taking any antibiotics ( $\mathrm{n}=14 ; 10$ females; mean age, 47 years), and the pouchitis+antibiotics group (BA) included patients who had pouchitis and who were taking some type of antibiotics ( $\mathrm{n}=7 ; 4$ males; mean age, 41 years). Ileal pouch endoscopy was performed, and fecal and tissue biopsy samples were collected for microbiological and histopathological analysis. RESULTS: There was a trend toward higher tissue biopsy concentrations of Bacteroides $s p$ in patients with pouchitis $(p=0,072)$. However, significantly higher concentrations were observed in group BA $(p=0,018)$ comparatively to group NB. The presence of strict anaerobes in tissue-associated flora increased the risk of development of pouchitis $(p=0,048)$. There were significantly higher fecal concentrations of Propionibacterium $s p$ in patients with pouchitis $(\mathrm{p}=0,009)$, and of Candida $s p(\mathrm{p}=0,043)$ and Fusobacterium $s p(p=0,045)$ in group BA in comparison to group NB. Colonic metaplasia was found in $15(36,6 \%)$ of 41 patients: 5 (25\%) of group NB, $8(57,1 \%)$ of group BNA and $2(28,6 \%)$ of group BA. However, no correlation was established between its presence with pouchitis $(\mathrm{p}=0,17)$. Atrophy degree of ileal pouch mucosa correlated well with time of postoperative follow-up $(p=0,055)$. CONCLUSIONS: A higher risk of developing pouchitis seems to be associated to higher concentrations of Bacteroides sp, as well as an increased concentration of anaerobic bacteria in the ileal pouch. The degree of mucosal atrophy, the presence of colonic metaplasia and the degree of acute or chronic inflammation does not seem to constitute risk factors for the development of pouchitis; the longer the time of postoperative follow-up, the greater the degree of mucosal atrophy.

Descriptors: 1. Proctocolitis 2. Pouchitis 3.Restorative Proctocolectomy 4.Microbiology 5.Histology 6.Risk factors 
1.INTRODUÇÃO 
A retocolectomia total restauradora associada à bolsa ileal (RR-BI) vem se consagrando como procedimento padrão-ouro no tratamento da Retocolite Ulcerativa (RCU) refratária ao tratamento clínico e da Polipose Adenomatosa Familial (PAF). Reduz o inconveniente da diarreia associada às anastomoses ileoanais diretas, ao armazenar as fezes líquidas, ao mesmo tempo em que preserva a função esfincteriana. No caso da RCU, passou a ser o procedimento cirúrgico eletivo mais utilizado ${ }^{1}$.

No entanto, a RR-BI não está isenta de complicações; a inflamação inespecífica da bolsa ileal, ou bolsite, é a mais comum a longo prazo, com incidências que variam de 14 a $59 \%^{2-12}$.

Embora a fisiopatologia das bolsites ainda permaneça controversa, há fortes evidências de que elas representem uma reativação da RCU, pois ocorrem quase que exclusivamente nos pacientes submetidos à RR-BI por RCU, e não por $\mathrm{PAF}^{7,12,13}$, sugerindo uma etiologia autoimune em indivíduo geneticamente predisposto. Outros fatores que apoiam essa teoria são a correlação entre a presença de manifestações extra-intestinais associada a um aumento do risco de desenvolvimento de bolsites $^{3,9,14}$ e a semelhança endoscópica e histopatológica observada entre os padrões das bolsites e da RCU ${ }^{15,16}$.

Além disso, a estase fecal, com conseqüente alteração da flora microbiana local, vem sendo defendida como um dos fatores mais relevantes na gênese deste fenômeno. Embora ainda não tenha sido isolado um agente bacteriano específico, a boa resposta clínica com o uso de metronidazol ou ciprofloxacina reforça essa teoria.

O isolamento de um agente etiológico microbiano específico, no entanto, permanece indefinido. Alguns autores identificaram aumento da relação 
anaeróbios/aeróbios em bolsas ileais comparativamente ao conteúdo de ileostomias após retocolectomia ${ }^{17}$; outros, citam diminuição desta relação em pacientes com bolsite comparativamente aos controles ${ }^{18,19}$. Há, ainda, os que não relatam diferenças significativas entre anaeróbios e aeróbios em pacientes com e sem bolsite ${ }^{16,20,21}$.

Observa-se, ainda, risco aumentado de desenvolvimento de bolsites em pacientes do sexo feminino ${ }^{6}$, com RCU extensa ou grave ${ }^{7}$, manifestações extracolônicas ${ }^{3,9,14}$, início precoce de desenvolvimento da doença ${ }^{3}$, uso de antiinflamatórios não-esteroidais ${ }^{10}$, polimorfismos do gene do antagonista do receptor da interleucina-1 e do $\mathrm{TNF}^{11}$ e presença do anticorpo perinuclear antineutrofílico citoplasmático (pANCA) ${ }^{22}$.

Um achado histopatológico freqüente nas bolsas ileais é a metaplasia colônica, em aproximadamente 50\% dos pacientes com bolsites e cerca de $18 \%$ dos pacientes submetidos à RR-BI sem bolsites ${ }^{18}$. 
2.OBJETIVO 
O objetivo deste estudo é caracterizar a microflora das bolsas ileais de pacientes operados por RCU com e sem bolsites, além de caracterizar as alterações histopatológicas mais freqüentes nas bolsas ileais e correlacioná-las com possíveis fatores de risco para o desenvolvimento de bolsites. 


\subsection{Pacientes}

Participaram do estudo 41 pacientes submetidos a RR-BI por retocolite ulcerativa (RCU) entre os anos de 1985 a 2006 no Hospital das Clínicas da Faculdade de Medicina da Universidade de São Paulo (HC-FMUSP), junto ao Serviço de Cirurgia do Cólon e Reto, do Departamento de Gastroenterologia. A técnica utilizada para a confecção da bolsa ileal foi a em “J”, proposta por Utsunomiya et al. em $1980^{23}$.

Foram incluídos 15 homens e 26 mulheres, com média de idade de 46,2 (variação de 23 a 66) anos. O tempo médio de duração da doença foi de 190,0 (variação de 15 a 312) meses e, o de seguimento pós-operatório, de 141,7 (variação de 24 a 276) meses. Trinta e três pacientes permaneceram com ileostomia temporária por um período médio de 22,3 (variação de 1 a 168) meses, enquanto 8 foram operados em apenas um tempo cirúrgico, com anastomose primária. Foram excluídos do estudo dois pacientes com diagnóstico anátomo-patológico da peça cirúrgica compatível com Doença de Crohn.

O Índice de Atividade da Bolsite, do inglês Pouchitis Disease Activity Index (PDAI), índice sugerido por Sandborn et al. $^{24}$, baseado em critérios clínicos, endoscópicos e histológicos padronizados, foi o critério utilizado para definir a presença ou ausência de quadro de bolsite nos pacientes avaliados, ao momento do estudo. Valores maiores ou iguais a 7 preenchem os critérios para bolsite, segundo este índice, conforme mostra a tabela 1: 
Tabela 1 - Critérios do Pouchitis Disease Activity Index (PDAI)

\begin{tabular}{|c|c|c|}
\hline Critério & Score & Total \\
\hline \multicolumn{3}{|l|}{ 1. Clínica: } \\
\hline \multicolumn{3}{|l|}{ Freqüência evacuatória } \\
\hline - Usual pós-operatória & 0 & \\
\hline - 1-2 evacuações/dia> que pós-operatória & 1 & \\
\hline - 3 evacuações> que pós-operatória & 2 & \\
\hline \multicolumn{3}{|l|}{ Sangramento retal } \\
\hline - Nenhum ou raro & 0 & \\
\hline - Diário & 1 & \\
\hline \multicolumn{3}{|l|}{ Urgência fecal ou cólicas abdominais } \\
\hline - Nenhuma & 0 & \\
\hline - Ocasional & 1 & \\
\hline - Freqüente & 2 & \\
\hline \multicolumn{3}{|l|}{ Febre (Temperatura $\left.>37,8^{\circ} \mathrm{C}\right)$} \\
\hline - Ausente & 0 & \\
\hline - Presente & 1 & \\
\hline \multicolumn{3}{|l|}{ 2. Achados endoscópicos: } \\
\hline - Edema & 1 & \\
\hline - Granulação & 1 & \\
\hline - Friabilidade & 1 & \\
\hline - Perda do padrão vascular & 1 & \\
\hline - Exsudato mucoso & 1 & \\
\hline - Ulceração & 1 & \\
\hline \multicolumn{3}{|l|}{ 3. Achados histopatológicos (Inflamação Aguda) } \\
\hline \multicolumn{3}{|l|}{ Infiltração leucocitária polimorfonuclear } \\
\hline - Leve & 1 & \\
\hline - Moderada + abscessos de criptas & 2 & \\
\hline - Grave + abscessos de criptas & 3 & \\
\hline \multicolumn{3}{|l|}{ Ulcerações por campo } \\
\hline - $<25 \%$ & 1 & \\
\hline - $25-50 \%$ & 2 & \\
\hline - $>50 \%$ & 3 & \\
\hline Total & & \\
\hline
\end{tabular}

FONTE: Sandborn WJ, et al. Pouchitis after ileal pouch-anal anastomosis: a pouchitis disease activity index. Mayo Clin Proc. 1994;69:409-15 
Assim, os pacientes foram divididos em três grupos: o grupo sem bolsite (NB) não apresentava inflamação da bolsa ileal ao momento da avaliação (n=20; 12 mulheres; média de idade, 47.5 anos); o grupo BNA apresentava bolsite e incluía pacientes sem uso de antibióticos ( $\mathrm{n}=14 ; 10$ mulheres; média de idade, 47 anos) e o grupo BA incluía pacientes com bolsite fazendo uso de antibióticos ( $\mathrm{n}=7 ; 4$ mulheres; média de idade, 41 anos).

O projeto de pesquisa e o termo de consentimento livre e esclarecido foram aprovados pela CAPPESQ (Comissão de Ética para Análise de Projetos de Pesquisa) do HC-FMUSP, sob o protocolo de número 1162/07. 


\subsection{Métodos}

\subsubsection{Avaliação endoscópica da bolsa ileal}

Todos os pacientes protocolados foram submetidos a avaliação endoscópica da bolsa ileal através de retoscópio rígido infantil estéril, sem preparo intestinal prévio. A descrição endoscópica das bolsas ileais foi realizada segundo os critérios do $P D A I^{24}$ já citados.

\subsubsection{Estudo Microbiológico}

Foram coletadas amostras de fezes diretamente da bolsa ileal, com alça estéril padronizada, de capacidade aproximada para $1 \mathrm{~g}$ de fezes. A seguir, após aspiração do conteúdo luminal, foram realizadas três biópsias com pinças estéreis nas áreas de maior comprometimento inflamatório, se presente, evitando-se as linhas de sutura e grampeamento. Dos fragmentos obtidos, um foi destinado a estudo microbiológico.

Tanto as amostras de fezes como os produtos de biópsias foram acondicionados em tubos do tipo eppendorff contendo $1 \mathrm{~mL}$ de solução pré-reduzida de tampão fosfatado. A seguir, o material coletado foi enviado ao laboratório de microbiologia do Instituto de Ciências Biomédicas da Universidade de São Paulo em prazo inferior a duas horas, a fim de se evitar contaminação.

Os produtos de biópsias foram, então, macerados. A seguir, tanto as amostras de fezes como o produto resultante das biópsias foram homogeneizados e diluídos 
nas razões decimais seriadas de $10^{-1}$ a $10^{-9}$, em tampão fosfatado e reduzido, mantendo as condições de assepsia. De cada tubo (exceto os referentes às diluições 6 e -8), com auxílio de alça de platina calibrada (11 mm de diâmetro), foi retirada amostra de $0,01 \mathrm{~mL}$ da solução que, a seguir, foi transferida para inoculação na superfície dos meios de cultura seletivos para bactérias microaerófilas, aeróbias e anaeróbias. Após quantificação (contagem de colônias), foi realizada identificação dos microrganismos isolados conforme procedimentos padronizados ${ }^{25-27}$. Para o cultivo das bactérias foram utilizados os seguintes meios:

\begin{tabular}{|c|c|}
\hline Staphylococcus sp & Chapman - Stone medium* \\
\hline Enterobactérias & MacConkey agar* \\
\hline Streptococcus sp & BHI-ágar sangue* \\
\hline Candida albicans & Ágar-Sabouraud** \\
\hline Enterococcus sp & Enterococcus selective agar** \\
\hline Peptococcus sp e & Phenylethialcohol agar* \\
\hline Peptostreptococcus sp & Phenylethialcohol agar* \\
\hline Veillonella sp & Veillonella medium* \\
\hline Fusobacterium sp & BHI $^{*}+$ Vit.K + Hemina + Estreptomicina \\
\hline Clostridium $s p$ & Reinforced Clostridium medium** \\
\hline Bacteroides do grupo B.fragilis & $\begin{array}{l}\text { Bacteroides fragilis Bile-esculin Agar Medium } \\
\text { (BBE) }\end{array}$ \\
\hline Bifidobacterium $s p$ & Bifidobacterium medium \\
\hline Propionibacterium sp & Propionibacterium medium \\
\hline Actinomyces sp & BHI* + Extrato de levedura \\
\hline $\begin{array}{lrr}\text { Bactérias } & \text { Anaeróbias } & \text { Gram- } \\
\text { negativas } & \text { produtoras } & \text { de } \\
\text { pigmento negro }\end{array}$ & Ágar sangue (TSA) + Vit.K + Hemina \\
\hline
\end{tabular}




\subsubsection{Estudo Histopatológico}

Os outros dois fragmentos coletados através da análise endoscópica foram destinados a avaliação histopatológica. Participaram do estudo três patologistas que, além dos critérios já citados do $P D A I^{24}$, descreveram os padrões observados segundo os seguintes critérios: grau de inflamação aguda, grau de inflamação crônica, grau de atividade, presença de metaplasia colônica, grau de atrofia da mucosa e grau de malignidade. Tais dados estão caracterizados na tabela 2:

\section{Tabela 2 - Graduação e critérios adotados para a caracterização histopatológica das bolsas ileais}

\begin{tabular}{|c|c|}
\hline Alteração Histológica & Graduação \\
\hline \multirow{3}{*}{$\begin{array}{c}\text { Grau de inflamação crônica (linfoplasmocitária e } \\
\text { eosinofílica) }\end{array}$} & Ausente ou Leve (0) \\
\hline & Moderada (1) \\
\hline & Intensa (2) \\
\hline \multirow{4}{*}{ Grau de inflamação aguda (polimorfonucleares) } & Ausente (0) \\
\hline & Leve (1) \\
\hline & Moderada (2) \\
\hline & Intensa (3) \\
\hline \multirow{4}{*}{ Grau de atividade } & Ausente (0) \\
\hline & Criptite Aguda (1) \\
\hline & $\begin{array}{l}\text { Microabscesso de cripta } \\
\text { (2) }\end{array}$ \\
\hline & Erosão ou ulceração (3) \\
\hline \multirow{2}{*}{ Presença de metaplasia colônica } & Ausente (0) \\
\hline & Presente (1) \\
\hline \multirow{3}{*}{ Grau de atrofia da mucosa } & Ausente (0) \\
\hline & Distorção de criptas (1) \\
\hline & Atrofia de criptas (2) \\
\hline \multirow{5}{*}{ Grau de malignidade (atipia citoarquitetural) } & Ausente (0) \\
\hline & Baixo grau (1) \\
\hline & Alto grau (2) \\
\hline & $\begin{array}{l}\text { Carcinoma intramucoso } \\
\text { (3) }\end{array}$ \\
\hline & Carcinoma invasivo (4) \\
\hline
\end{tabular}


4. ESTATÍSTICA 
Foi utilizada a análise de Kruskal-Wallis e de Regressão Logística para a avaliação quantitativa de microrganismos por grupo estudado e o Teste Exato de Fisher e Teste T de Student não-pareado para a correlação dos critérios anátomopatológicos com os mesmos grupos.

Além disso, foi aplicado o Teste de Normalidade de Shapiro-Wilk sobre os grupos NB, BNA e BA tanto em relação ao tempo de doença ( $p=0,661,0,589$ e 0,442, respectivamente) como ao tempo de evolução pós-operatória ( $p=0,389,0,051$ e 0,218 , respectivamente). Isso nos permitiu utilizar, a seguir, o método Anova entre os mesmos grupos, o que nos fez concluir que se trata de três grupos homogêneos, tanto no que diz respeito ao tempo de doença $(p=0,222)$ como ao tempo de evolução pós-operatória $(p=0,139)$. 
5. RESULTADOS 


\subsection{Análise microbiológica dos produtos de biópsias}

Embora não haja diferença estatisticamente significativa dentre os microrganismos isolados nos diferentes grupos, observa-se uma tendência a predomínio de Bacteroides sp nos grupos BNA e BA, ou seja, em pacientes com bolsites, sem e em uso de antibióticos, respectivamente $(p=0,072)$ Os resultados obtidos estão expressos na tabela 3:

Tabela 3 - Correlação entre as médias das concentrações dos microrganismos isolados, expressos em $\log _{10}$ Unidades Formadoras de Colônias (UFC) / g de tecido, nos grupos NB, BNA e BA

\begin{tabular}{|l|c|c|c|c|c|c|c|}
\hline \multirow{2}{*}{ Microrganismo } & \multicolumn{2}{|c|}{ Grupo NB } & \multicolumn{2}{c|}{ Grupo BNA } & \multicolumn{2}{c|}{ Grupo BA } & $p$ \\
\hline & Média & $\begin{array}{c}\text { Erro- } \\
\text { padrão }\end{array}$ & Média & $\begin{array}{c}\text { Erro- } \\
\text { padrão }\end{array}$ & Média & $\begin{array}{c}\text { Erro- } \\
\text { padrão }\end{array}$ \\
\hline Bacteroides sp & 0,00 & 0,00 & 0,21 & 0,20 & 0,57 & 0,26 & 0,07 \\
\hline Candida sp & 0,00 & 0,00 & 0,21 & 0,36 & 0,00 & 0,00 & 0,14 \\
\hline Clostridium sp & 0,00 & 0,00 & 0,21 & 0,06 & 0,00 & 0,00 & 0,38 \\
\hline Corynebacterium & 0,05 & 0,50 & 0,00 & 0,00 & 0,00 & 0,00 & 0,59 \\
\hline Enterobacter sp & 0,30 & 0,16 & 0,36 & 0,20 & 0,14 & 0,09 & 0,90 \\
\hline E. coli & 2,25 & 0,44 & 1,36 & 0,36 & 2,14 & 0,58 & 0,43 \\
\hline Fusobacterium sp & 0,10 & 0,11 & 0,07 & 0,06 & 0,00 & 0,00 & 0,79 \\
\hline Klebsiella sp & 0,35 & 0,16 & 0,50 & 0,18 & 0,43 & 0,19 & 0,81 \\
\hline Propionibacterium & 0,00 & 0,00 & 0,14 & 0,13 & 0,00 & 0,00 & 0,38 \\
\hline Proteus sp & 0,10 & 0,11 & 0,07 & 0,06 & 0,00 & 0,00 & 0,79 \\
\hline Serratia sp & 0,05 & 0,05 & 0,00 & 0,00 & 0,00 & 0,00 & 0,59 \\
\hline Staphylococcus sp & 0,10 & 0,11 & 0,00 & 0,00 & 0,14 & 0,09 & 0,38 \\
\hline Veillonella sp & 0,25 & 0,13 & 0,50 & 0,18 & 0,29 & 0,11 & 0,56 \\
\hline
\end{tabular}

No entanto, ao analisarmos separadamente as correlações entre os grupos quanto às médias de Bacteroides sp, observamos diferença estatisticamente significativa entre os grupos NB e BA $(\boldsymbol{p}=\mathbf{0 , 0 1 8})$, o que não ocorre entre os grupos 
NB e BNA $(p=0,094)$ ou BNA e BA $(p=0,446)$, conforme demonstram a tabela 4 e o gráfico 1:

Tabela 4 - Comparação entre as médias de Bacteroides $s p$, expressas em $\log _{10}$ UFC g/ tecido, nos grupos NB, BNA e BA

\begin{tabular}{|l|l|l|}
\hline Grupo & Média & Erro-Padrão \\
\hline NB & 0,0000 & 0,0000 \\
\hline BNA & 0,2143 & 0,1547 \\
\hline BA & 0,5714 & 0,4857 \\
\hline
\end{tabular}

\section{Gráfico 1 - Comparação entre as médias de Bacteroides $s p$, expressas em $\log _{10}$ UFC g/ tecido, nos grupos NB, BNA e BA}

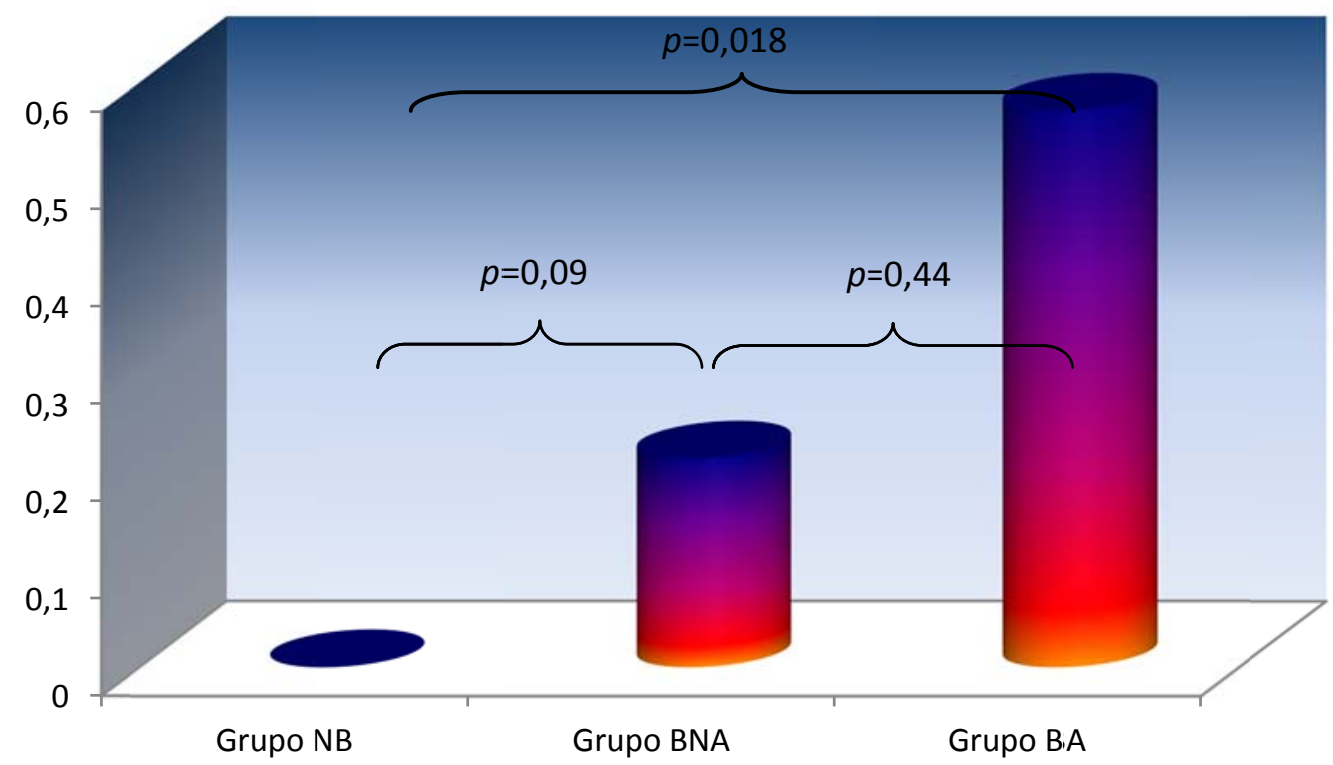

Ao considerarmos os microrganismos como dois grandes grupos, aeróbios / facultativos, de um lado, e anaeróbios, de outro, observamos que não há diferença estatisticamente significativa tanto dentre as médias de aeróbios / facultativos ( $p=0,183)$, como dentre os anaeróbios $(p=0,110)$, nos 3 grupos avaliados, conforme observamos nas tabelas 5 e 6 : 
Tabela 5 - Comparação entre as médias de aeróbios, expressas em $\log _{10}$ UFC g/ tecido, nos grupos NB, BNA e BA

\begin{tabular}{|l|l|l|}
\hline Grupo & Média & Erro-Padrão \\
\hline NB & 1,9983 & 0,2619 \\
\hline BNA & 1,3179 & 0,2846 \\
\hline BA & 1,829 & 0,7532 \\
\hline
\end{tabular}

Tabela 6 - Comparação entre as médias de anaeróbios, expressas em $\log _{10}$ UFC g/ tecido, nos grupos NB, BNA e BA

\begin{tabular}{|l|l|l|}
\hline Grupo & Média & Erro-Padrão \\
\hline NB & 0,1989 & 0,0930 \\
\hline BNA & 0,6420 & 0,1999 \\
\hline BA & 0,4875 & 0,3192 \\
\hline
\end{tabular}

No entanto, ao estabelecermos um modelo de regressão logística para os mesmos grupos, constatamos que, apesar de não haver correlação significativa entre a presença de aeróbios e o risco de bolsites, há um aumento da probabilidade de ocorrência de bolsites à medida que aumenta a concentração de anaeróbios na bolsa ileal, como demonstram as tabelas 7, 8 e 9:

Tabela 7 - Modelo logístico para risco de bolsites por presença de aeróbios/anaeróbios

\begin{tabular}{|l|l|l|l|}
\hline Coeficiente & Estimativa & Erro -Padrão & $\boldsymbol{p}$ \\
\hline Intercepto & 0,5477 & 0,1350 & 0,0002 \\
\hline Aeróbios & $-0,0763$ & 0,0584 & 0,1989 \\
\hline Anaeróbios & 0,2430 & 0,1189 & 0,0480 \\
\hline
\end{tabular}

Tabela 8 - Modelo logístico para risco de bolsites por presença de aeróbios

\begin{tabular}{|l|l|l|l|}
\hline Coeficiente & Estimativa & Erro-Padrão & $\boldsymbol{p}$ \\
\hline Intercepto & 0,6447 & 0,1314 & $<0,0001$ \\
\hline Aeróbios & $-0,0763$ & 0,0607 & 0,2160 \\
\hline
\end{tabular}


Tabela 9 - Modelo logístico para risco de bolsites por presença de anaeróbios

\begin{tabular}{|l|l|l|l|}
\hline Coeficiente & Estimativa & Erro-Padrão & $\boldsymbol{p}$ \\
\hline Intercepto & 0,4152 & 0,0900 & $<0,0001$ \\
\hline Anaeróbios & 0,2429 & 0,1200 & 0,0498 \\
\hline
\end{tabular}

Portanto, com base nos dados acima, podemos afirmar que cada unidade (em base logarítmica de 10) de UFCs de bactérias anaeróbias / g de tecido aumenta em 27,5\% [IC 95\%: 0,8\%; 61,3\%] o risco de bolsites. 


\subsection{Análise microbiológica das amostras fecais}

Ao analisarmos as amostras fecais, verificamos que, apesar da tendência a um aumento na concentração de alguns microrganismos nos grupos BNA e BA (como Candida sp, Fusobacterium sp e Proteus sp), este predomínio somente é estatisticamente significativo no caso do anaeróbio Propionibacterium $s p(p=0,009)$, como expressa a tabela 10:

Tabela 10 - Correlação entre as médias das concentrações dos microrganismos isolados, expressos em $\log _{10}$ Unidades Formadoras de Colônias (UFC) / g de fezes nos grupos NB, BNA e BA

\begin{tabular}{|l|l|l|l|c|c|c|c|}
\hline & \multicolumn{2}{|c|}{ Grupo NB } & \multicolumn{2}{c|}{ Grupo BNA } & \multicolumn{2}{c|}{ Grupo BA } & \\
\hline Microrganismo & Média & $\begin{array}{c}\text { Erro- } \\
\text { padrão }\end{array}$ & Média & $\begin{array}{c}\text { Erro- } \\
\text { padrão }\end{array}$ & Média & $\begin{array}{c}\text { Erro- } \\
\text { padrão }\end{array}$ & p \\
\hline Aeromonas sp & 0,00 & 0,00 & 0,07 & 0,05 & 0,00 & 0,00 & 0,38 \\
\hline Bacillus sp & 0,10 & 0,06 & 0,00 & 0,00 & 0,00 & 0,00 & 0,34 \\
\hline Bacterionema sp & 0,05 & 0,04 & 0,14 & 0,10 & 0,00 & 0,00 & 0,77 \\
\hline Bacteroides sp & 0,95 & 0,26 & 1,29 & 0,29 & 1,14 & 0,36 & 0,75 \\
\hline Candida sp & 0,30 & 0,14 & 0,57 & 0,16 & 1,57 & 0,37 & 0,10 \\
\hline Clostridium sp & 0,45 & 0,17 & 0,14 & 0,07 & 0,00 & 0,00 & 0,27 \\
\hline Corynebacterium & 0,25 & 0,11 & 0,14 & 0,10 & 0,86 & 0,23 & 0,14 \\
\hline Edwardsiella sp & 0,10 & 0,09 & 0,00 & 0,00 & 0,00 & 0,00 & 0,59 \\
\hline Enterobacter sp & 1,80 & 0,36 & 2,14 & 0,38 & 1,00 & 0,33 & 0,35 \\
\hline E.coli & 2,80 & 0,41 & 1,86 & 0,42 & 4,14 & 0,61 & 0,20 \\
\hline Fusobacterium sp & 1,15 & 0,27 & 1,64 & 0,28 & 2,71 & 0,41 & 0,10 \\
\hline Klebsiella sp & 1,70 & 0,37 & 2,21 & 0,40 & 0,43 & 0,15 & 0,15 \\
\hline Lactobacillus sp & 0,05 & 0,04 & 0,14 & 0,10 & 0,43 & 0,22 & 0,68 \\
\hline Micrococcus sp & 0,15 & 0,13 & 0,14 & 0,07 & 0,57 & 0,22 & 0,27 \\
\hline Peptococcus sp & 0,20 & 0,13 & 0,07 & 0,05 & 0,71 & 0,36 & 0,83 \\
\hline Propionibacterium & 0,00 & 0,00 & 0,86 & 0,28 & 1,14 & 0,30 & 0,01 \\
\hline Proteus sp & 1,15 & 0,34 & 0,64 & 0,21 & 3,29 & 0,61 & 0,06 \\
\hline & & & & & & & continua \\
\hline
\end{tabular}


Tabela 10 - (conclusão) Correlação entre as médias das concentrações dos microrganismos isolados, expressos em $\log _{10}$ Unidades Formadoras de Colônias (UFC) / g de fezes nos grupos NB, BNA e BA

\begin{tabular}{|l|c|c|c|c|c|c|c|}
\multirow{2}{*}{ Microrganismo } & \multicolumn{2}{|c|}{ Grupo NB } & \multicolumn{2}{c|}{ Grupo BNA } & \multicolumn{2}{c|}{ Grupo BA } & \\
\cline { 3 - 9 } & Média & $\begin{array}{c}\text { Erro- } \\
\text { padrão }\end{array}$ & Média & $\begin{array}{c}\text { Erro- } \\
\text { padrão }\end{array}$ & Média & $\begin{array}{c}\text { Erro- } \\
\text { padrão }\end{array}$ & $p$ \\
\hline Pseudomonas sp & 0,25 & 0,12 & 0,21 & 0,11 & 0,00 & 0,00 & 0,56 \\
\hline Rodothorula sp & 0,00 & 0,00 & 0,14 & 0,10 & 0,00 & 0,00 & 0,38 \\
\hline Serratia sp & 0,30 & 0,14 & 0,00 & 0,00 & 0,00 & 0,00 & 0,19 \\
\hline Staphylococcus & 0,40 & 0,12 & 0,64 & 0,19 & 1,43 & 0,33 & 0,17 \\
sp & & & & & & & \\
\hline Streptococcus sp & 0,00 & 0,00 & 0,00 & 0,00 & 0,14 & 0,07 & 0,09 \\
\hline Veillonella sp & 1,55 & 0,32 & 2,07 & 0,30 & 3,29 & 0,44 & 0,15 \\
\hline
\end{tabular}

Neste caso, avaliando-se separadamente os grupos entre si, observamos diferença estatisticamente significativa tanto entre os grupos NB e BNA $(p=0,005)$, como entre os grupos NB e BA $(p=0,003)$. O mesmo não ocorre entre os grupos BNA e BA $(p=0,699)$, conforme mostra a tabela 11:

Tabela 11 - Comparação entre as médias de Propionibacterium sp, expressas em $\log _{10}$ UFC g/ tecido, nos grupos NB, BNA e BA

\begin{tabular}{|l|l|l|}
\hline Grupo & Média & Erro-Padrão \\
\hline NB & 0,0000 & 0,0000 \\
\hline BNA & 0,8571 & 0,3902 \\
\hline BA & 1,1429 & 0,5948 \\
\hline
\end{tabular}

No caso da Candida sp, embora não haja diferença significativa entre os três grupos analisados conjuntamente, observamos que há predomínio significativo deste microrganismo no grupo BA comparativamente ao grupo NB $(p=0,043)$. Não há 
diferença entre os grupos NB e BNA $(p=0,288)$ ou entre os grupos BNA e BA $(p=0,228)$, como demonstra a tabela 12 :

Tabela 12 - Comparação entre as médias de Candida sp, expressas em $\log _{10}$ UFC g/ tecido, nos grupos NB, BNA e BA

\begin{tabular}{|l|l|l|}
\hline Grupo & Média & Erro-Padrão \\
\hline NB & 0,3000 & 0,1638 \\
\hline BNA & 0,5714 & 0,2276 \\
\hline BA & 1,5714 & 0,7190 \\
\hline
\end{tabular}

Similarmente ao observado anteriormente, constatamos que, na análise de Fusobacterium sp, há diferença significativa entre os grupos NB e BA $(p=0,045)$, o que não ocorre entre os grupos NB e BNA $(p=0,244)$ ou entre os grupos BNA e BA $(p=0,234)$ :

Tabela 13 - Comparação entre as médias de Fusobacterium sp, expressas em $\log _{10}$ UFC g/tecido, nos grupos NB, BNA e BA

\begin{tabular}{|l|l|l|}
\hline Grupo & Média & Erro-Padrão \\
\hline NB & 1,1500 & 0,7190 \\
\hline BNA & 1,6429 & 0,3867 \\
\hline BA & 2,7143 & 0,8081 \\
\hline
\end{tabular}

No caso de Proteus sp, há diferença significativa apenas entre os grupos BNA e BA $(p=0,022)$, o que não se repete entre os grupos NB e BNA $(p=0,513)$ ou entre os grupos NB e BA $(p=0,072)$ : 
Tabela 14 - Comparação entre as médias de Proteus sp, expressas em $\log _{10}$ UFC g/ tecido, nos grupos NB, BNA e BA

\begin{tabular}{|l|l|l|}
\hline Grupo & Média & Erro-Padrão \\
\hline NB & 1,1500 & 0,3992 \\
\hline BNA & 0,6429 & 0,2891 \\
\hline BA & 3,2857 & 1,1895 \\
\hline
\end{tabular}

Do mesmo modo como analisamos previamente os produtos de biópsias, consideramos os microrganismos como dois grandes grupos. Assim, não constatamos diferença estatisticamente significativa entre os grupos NB, BNA e BA, tanto em relação aos aeróbios/facultativos $(p=0,317)$ como em relação aos anaeróbios $(p=0,294)$, conforme as tabelas 15 e 16 :

Tabela 15 - Comparação entre as médias de aeróbios, expressas em $\log _{10}$ UFC g/ fezes, nos grupos NB, BNA e BA

\begin{tabular}{|l|l|l|}
\hline Grupo & Média & Erro-Padrão \\
\hline NB & 3,0664 & 0,3127 \\
\hline BNA & 2,7135 & 0,3823 \\
\hline BA & 4,4525 & 0,8234 \\
\hline
\end{tabular}

Tabela 16 - Comparação entre as médias de anaeróbios, expressas em $\log _{10}$ UFC g/ fezes, nos grupos NB, BNA e BA

\begin{tabular}{|l|l|l|}
\hline Grupo & Média & Erro-Padrão \\
\hline NB & 1,8359 & 0,2640 \\
\hline BNA & 1,9298 & 0,3506 \\
\hline BA & 2,9314 & 0,7024 \\
\hline
\end{tabular}

Ao aplicarmos o modelo de regressão logística para estes grupos, observamos que não há efeito significativo, tanto quanto à presença de aeróbios/facultativos $(p=0,903)$ como quanto a anaeróbios $(p=0,382)$, no risco de bolsites, o que é demonstrado nas tabelas 17, 18 e 19: 
Tabela 17 - Modelo logístico para risco de bolsites quanto a presença de aeróbios/anaeróbios

\begin{tabular}{|l|l|l|l|}
\hline Coeficiente & Estimativa & Erro-Padrão & $\boldsymbol{P}$ \\
\hline Intercepto & 0,4073 & 0,1815 & 0,0308 \\
\hline Aeróbios & $-0,0073$ & 0,0594 & 0,9034 \\
\hline Anaeróbios & 0,0623 & 0,0704 & 0,3819 \\
\hline
\end{tabular}

Tabela 18 - Modelo logístico para risco de bolsites quanto a presença de aeróbios

\begin{tabular}{|l|l|l|l|}
\hline Coeficiente & Estimativa & Erro-Padrão & $P$ \\
\hline Intercepto & 0,4430 & 0,1765 & 0,0163 \\
\hline Aeróbios & 0,0217 & 0,0495 & 0,6628 \\
\hline
\end{tabular}

Tabela 19 - Modelo logístico para risco de bolsites quanto a presença de anaeróbios

\begin{tabular}{|l|l|l|l|}
\hline Coeficiente & Estimativa & Erro-Padrão & $P$ \\
\hline Intercepto & 0,3939 & 0,14304 & 0,0089 \\
\hline Anaeróbios & 0,0576 & 0,05801 & 0,3272 \\
\hline
\end{tabular}




\subsection{Avaliação histopatológica dos produtos de biópsias}

Através da avaliação histopatológica dos produtos de biópsias, pudemos observar que, quanto maior o tempo de seguimento pós-operatório, maior o grau de atrofia da mucosa $(p=0,055)$. No entanto, não há correlação entre esta alteração histopatológica e o tempo decorrido da doença $(p=0,5632)$. Tais dados são ilustrados pelo gráfico 2 e a tabela 20, onde zero corresponde a ausência de atrofia e, 1 , a distorção das criptas (não foi observada atrofia total das criptas):

Gráfico 2 - Grau de atrofia mucosa correlacionada ao tempo decorrido da cirurgia

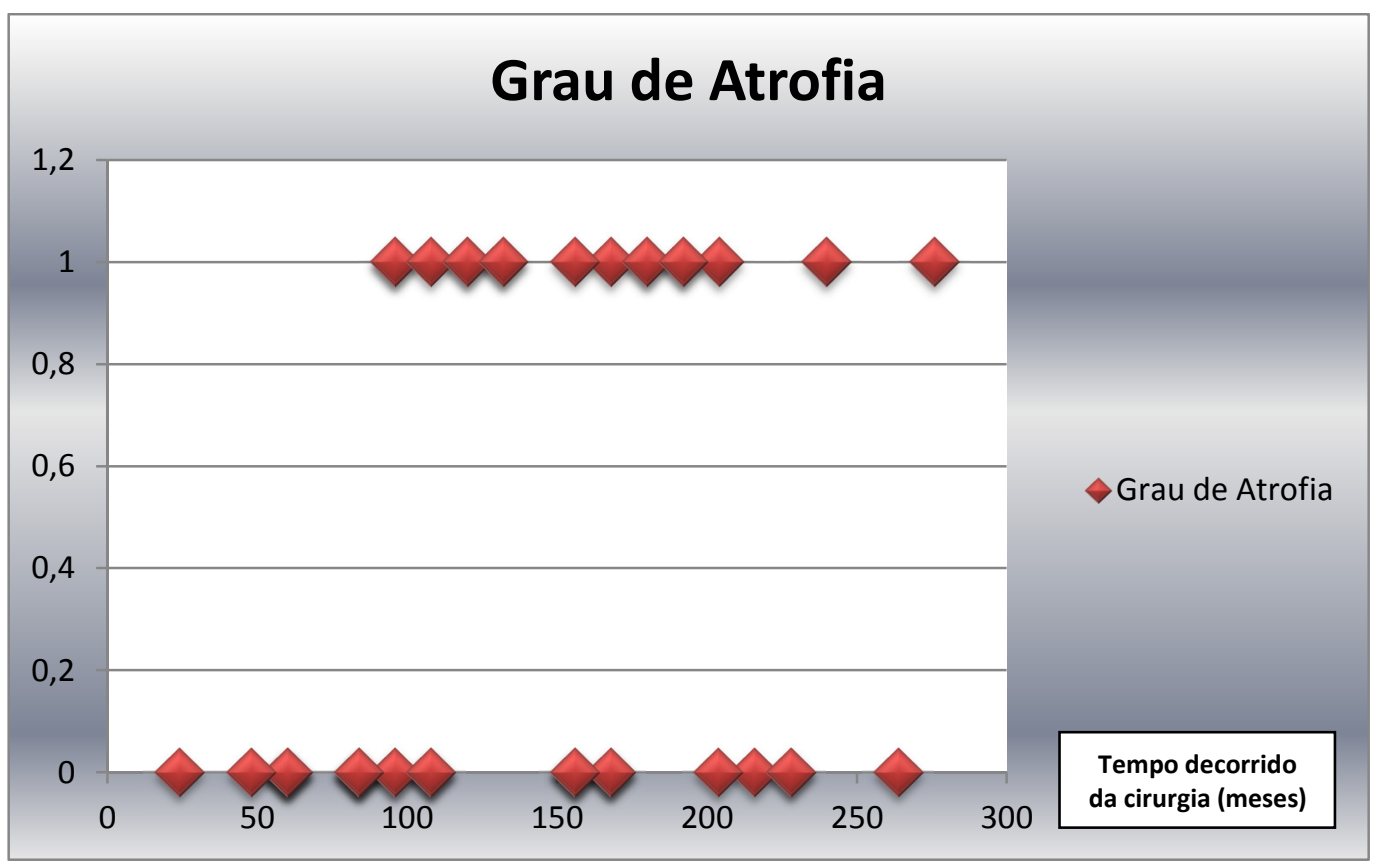


Tabela 20 - Correlação entre os tempos de doença e de cirurgia com o grau de atrofia mucosa, segundo o Teste $\mathbf{T}$ de Student não-pareado

\begin{tabular}{|c|c|c|c|c|c|c|}
\hline $\begin{array}{l}\text { Grau de } \\
\text { Atrofia }\end{array}$ & \multicolumn{3}{|c|}{ Tempo de doença } & \multicolumn{3}{|c|}{ Tempo de cirurgia } \\
\hline & Média & $\begin{array}{c}\text { Erro- } \\
\text { padrão }\end{array}$ & $p$ & Média & $\begin{array}{c}\text { Erro- } \\
\text { padrão }\end{array}$ & $p$ \\
\hline 0 & 184,6154 & 13,28076 & \multirow{2}{*}{0,5632} & 126,0000 & $1: 2,75617$ & \multirow{2}{*}{0,0552} \\
\hline$\overline{1}$ & 199,6875 & 22,04535 & & 162,0000 & $1: 2,96148$ & \\
\hline
\end{tabular}

A figura 1, a seguir, representa o padrão histopatológico observado em bolsas ileais normais, enquanto que a figura 2 ilustra a atrofia mucosa observada em alguns pacientes:
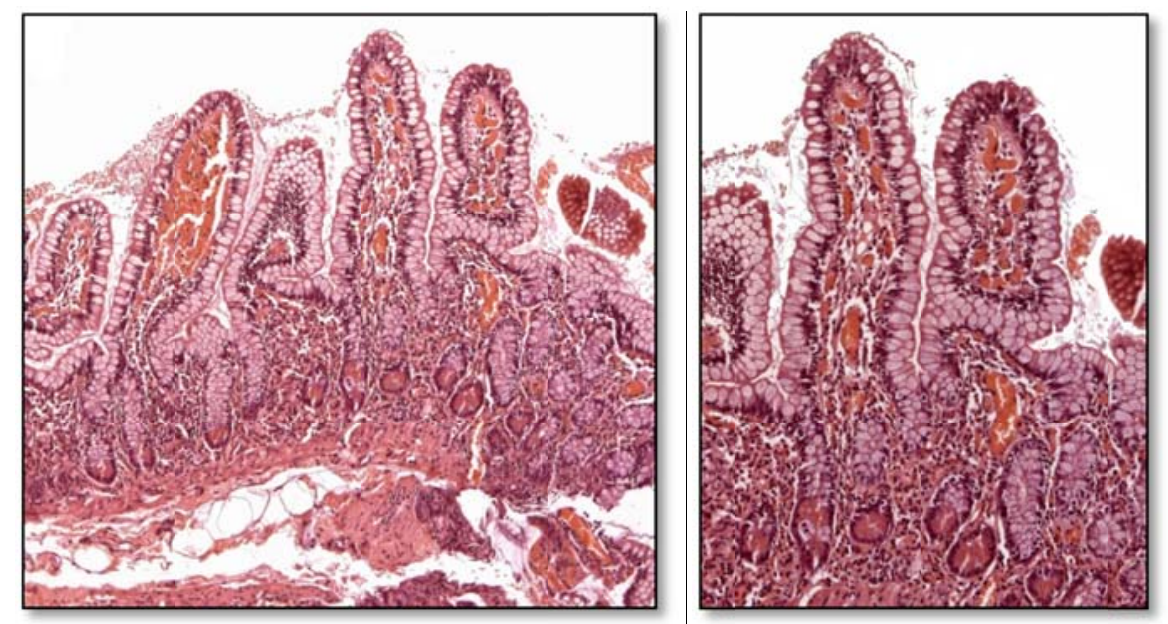

Figura 1 - Mucosa de bolsa ileal normal, onde a relação vilo:cripta corresponde a 3:1. Presença de células de Paneth, bordo “em escova” e menor quantidade de células caliciformes em relação ao cólon 

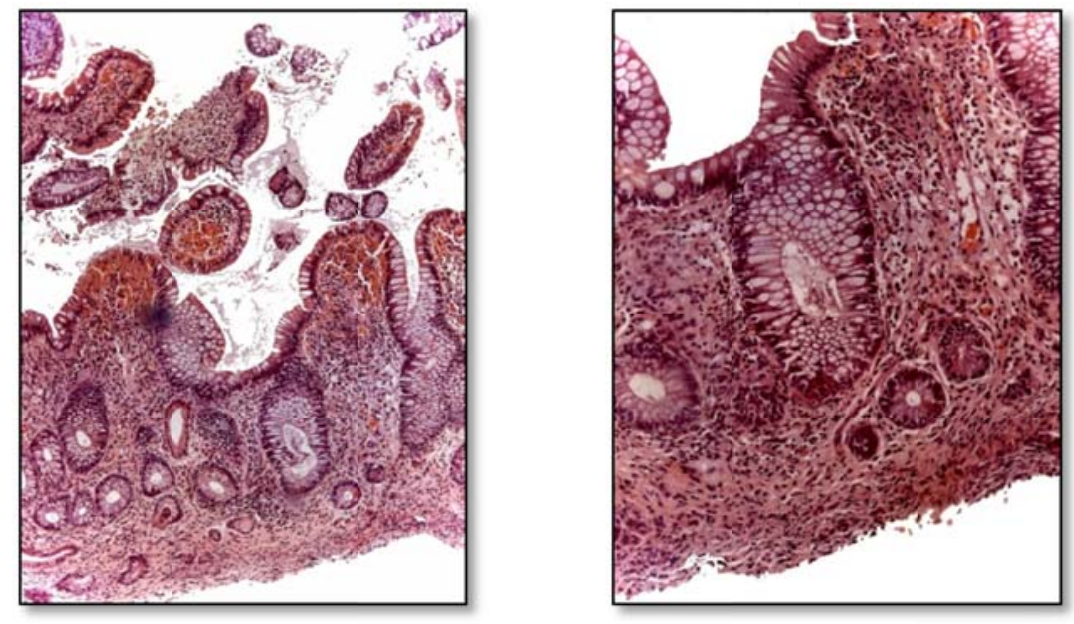

Figura 2 - Atrofia mucosa. Relação vilo-cripta=1:1, alargamento das vilosidades, infiltrado linfocitário e fibroplasia da lâmina própria

A metaplasia colônica foi observada em 15 (36,6\%) dos 41 pacientes: 5 (25\%) do grupo NB, 8 (57,1\%) do grupo BNA e 2 (28,6\%) do grupo BA. Não foram observadas displasias ou alterações neoplásicas.

Não houve diferença estatisticamente significativa entre:

- Os grupos NB, BNA e BA e o grau de atrofia da mucosa $(p=0,5203)$ figura 2

- Os grupos NB, BNA e BA e a presença de metaplasia colônica ( $p=0,1697)$ - figura 3

- Os grupos NB, BNA e BA e o grau de inflamação aguda $(p=0,4434)$ figura 4

- Os grupos NB, BNA e BA e o grau de inflamação crônica $(p=0,9999)$ - figura 5

Tais dados são expressos na tabela 21, a seguir: 
Tabela 21 - Correlação entre a presença de metaplasia colônica, grau de atrofia mucosa, grau de inflamação aguda e grau de inflamação crônica com os grupos NB, BNA e BA e respectivo número de pacientes, segundo o Teste exato de Fisher

\begin{tabular}{|c|c|c|c|c|c|c|c|c|c|c|c|}
\hline \multirow{4}{*}{ Grupos } & \multicolumn{2}{|c|}{$\begin{array}{l}\text { Metaplasia } \\
\text { colônica }\end{array}$} & \multicolumn{2}{|c|}{$\begin{array}{l}\text { Grau de } \\
\text { Atrofia } \\
\text { Mucosa }\end{array}$} & \multicolumn{4}{|c|}{$\begin{array}{c}\text { Grau de } \\
\text { Inflamação Aguda }\end{array}$} & \multicolumn{3}{|c|}{$\begin{array}{c}\text { Grau de } \\
\text { Inflamação } \\
\text { Crônica }\end{array}$} \\
\hline & \multicolumn{2}{|c|}{$p$} & \multicolumn{2}{|c|}{$p$} & \multicolumn{4}{|c|}{$p$} & \multicolumn{3}{|c|}{$p$} \\
\hline & \multicolumn{2}{|c|}{0,1697} & \multicolumn{2}{|c|}{0,5203} & \multicolumn{4}{|c|}{0,4434} & \multicolumn{3}{|c|}{0,9999} \\
\hline & Não & Sim & 0 & 1 & 0 & 1 & 2 & 3 & 0 & 1 & 2 \\
\hline NB & 15 & 5 & 13 & 7 & 6 & 10 & 4 & 0 & 9 & 8 & 3 \\
\hline BNA & 6 & 8 & 10 & 4 & 4 & 6 & 1 & 3 & 7 & 5 & 2 \\
\hline BA & 5 & 2 & 3 & 4 & 3 & 3 & 1 & 0 & 3 & 3 & 1 \\
\hline
\end{tabular}
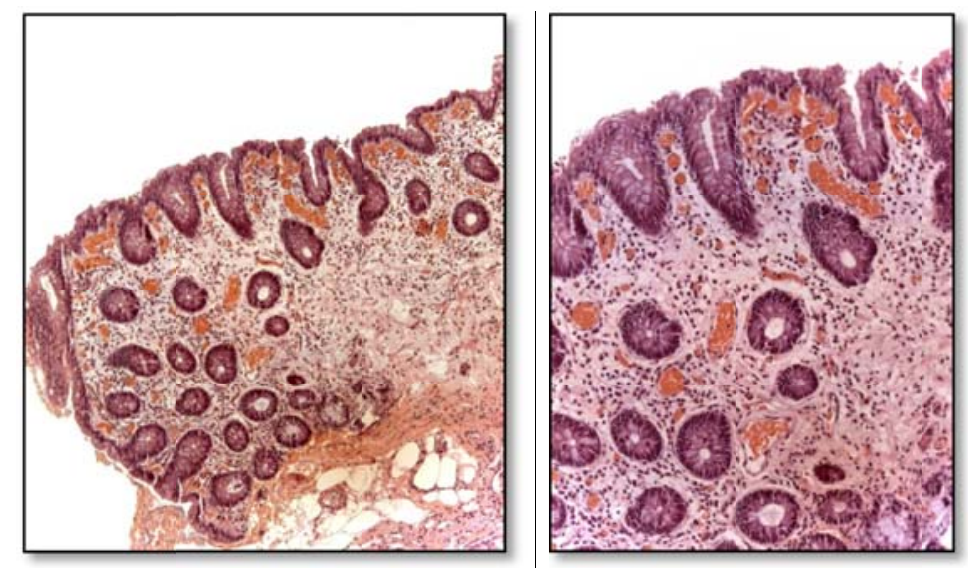

Figura 3 - Metaplasia Colônica. São observadas apenas criptas. Ausência de vilos ou células de Paneth
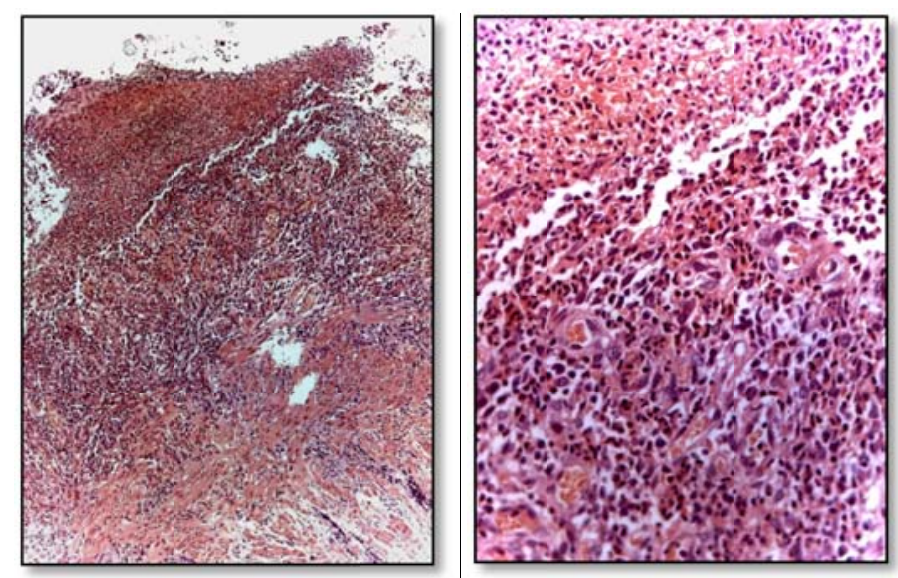

Figura 4 - Inflamação aguda com erosões. Observa-se tampão fibrinoleucocitário, presença de erosões na camada muscular da mucosa e tecido de granulação adjacente com neoangiogênese 

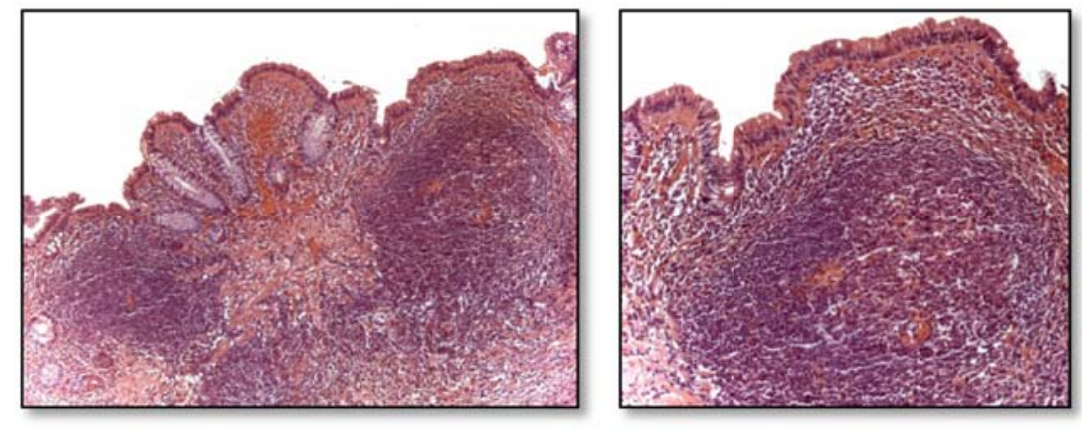

Figura 5 - Inflamação Crônica. Observa-se a presença de folículos linfóides reacionais com centros germinativos

Conforme mostram as tabelas 22, 23 e 24, não houve também diferença significativa entre:

- O tempo de duração da doença e a presença de metaplasia colônica $(p=0,4670)$

- O tempo de seguimento pós-operatório e a presiença de metaplasia colônica $(p=0,2041)$

Tabela 22 - Correlação entre os tempos de doença e de cirurgia com a presença de metaplasia colônica, segundo o Teste $\mathbf{T}$ de Student não-pareado

\begin{tabular}{|c|c|c|c|c|c|c|}
\hline \multirow[t]{2}{*}{$\begin{array}{l}\text { Metaplasia } \\
\text { Colônica }\end{array}$} & \multicolumn{3}{|c|}{ Tempo de doença } & \multicolumn{3}{|c|}{ Tempo de cirurgia } \\
\hline & Média & Erro-padrão & $p$ & Média & $\begin{array}{c}\text { Erro- } \\
\text { padrão }\end{array}$ & $p$ \\
\hline Não & 183,8077 & 15,57118 & \multirow{2}{*}{0,4670} & 130,1538 & 12,35820 & \multirow{2}{*}{0,2041} \\
\hline$\overline{\operatorname{Sim}}$ & 201,0000 & 17,44133 & & 155,2500 & $\mathbf{1 4 , 9 1 8 5 3}$ & \\
\hline & $\begin{array}{l}\text { O grau } \\
(p=0,239\end{array}$ & inflamação & ônica & o grau & atrofia & mucosa \\
\hline & $\begin{array}{l}\text { O grau d } \\
(p=0,827\end{array}$ & inflamação c & & resença & meta & colônica \\
\hline
\end{tabular}


Tabela 23 - Correlação entre os graus de atrofia mucosa e presença de metaplasia colônica com o grau de inflamação crônica, segundo o Teste Exato de Fisher

\begin{tabular}{|l|l|l|l|l|l|l|l|}
$\begin{array}{c}\text { Grau de Inflamação } \\
\text { Crônica }\end{array}$ & \multicolumn{3}{|c|}{ Grau de Atrofia Mucosa } & \multicolumn{3}{|c|}{ Metaplasia Colônica } \\
\hline & \multicolumn{2}{|c|}{$\mathbf{0}$} & $\mathbf{1}$ & $\boldsymbol{p}$ & \multicolumn{1}{|c|}{ Não } & Sim & $\boldsymbol{p}$ \\
\hline $\mathbf{0}$ & 13 & 6 & 0,2396 & 12 & 7 & \\
\hline $\mathbf{1}$ & 8 & 9 & & 11 & 6 & 0,8275 \\
\hline $\mathbf{2}$ & 5 & 1 & 3 & 3 & \\
\hline
\end{tabular}

- O tempo de duração da doença e o grau de inflamação crônica $(p=0,2031)$

- O tempo de seguimento pós-operatório e o grau de inflamação crônica $(p=0,4980)$

Tabela 24 - Correlação entre os tempos de doença e de cirurgia com o grau de inflamação crônica, segundo análise de variância

\begin{tabular}{|c|c|c|c|c|c|c|}
\hline \multirow{2}{*}{$\begin{array}{c}\text { Grau de } \\
\text { Inflamação } \\
\text { Crônica }\end{array}$} & \multicolumn{3}{|c|}{ Tempo de doença } & \multicolumn{3}{|c|}{ Tempo de cirurgia } \\
\hline & Média & $\begin{array}{c}\text { Erro- } \\
\text { padrão }\end{array}$ & $p$ & Média & $\begin{array}{c}\text { Erro- } \\
\text { padrão }\end{array}$ & $p$ \\
\hline 0 & 165,6316 & 15,69207 & \multirow{3}{*}{0,2031} & 127,5789 & 13,11361 & \multirow{3}{*}{0,4980} \\
\hline 1 & 219,5294 & 18,08113 & & 155,2941 & 13,78505 & \\
\hline$\overline{2}$ & 186,0000 & 33,76389 & & 134,0000 & 37,10526 & \\
\hline
\end{tabular}


Desde sua descrição inicial em 1978, por Parks e Nicholls ${ }^{28}$, a bolsa ileal vem sendo amplamente utilizada como forma de se obter diminuição do número de evacuações com preservação esfincteriana em pacientes submetidos a retocolectomia total. No caso da RCU, excetuando-se suas contra-indicações (formas agudas complicadas, disfunção esfincteriana, desnutrição ou coexistência de câncer da porção média ou distal do reto ou ânus), passou a ser o procedimento cirúrgico eletivo mais utilizado ${ }^{1}$.

Até então, os pacientes permaneciam com ileostomia terminal definitiva de Brooke $^{29}$ ou anastomose ileoanal e consequente alto número de evacuações diárias. O primeiro reservatório, em questão, utilizava três alças de intestino delgado, com configuração em "S". Desde então, outras bolsas ileais foram descritas ${ }^{30,31}$. No entanto, a técnica em "J", descrita por Utsunomiya ${ }^{23}$, passou a ser a mais utilizada mundialmente, devido à facilidade técnica e bons resultados a longo prazo, sendo a técnica utilizada pelo grupo de Cirurgia do Cólon e Reto da FMUSP desde 1985 $5^{32-34}$, e a empregada neste estudo.

Mesmo considerando suas vantagens em relação às técnicas empregadas anteriormente, a técnica de reservatório ileal em "J" apresenta complicações, sendo a bolsite a mais frequente. Em nosso serviço, foi verificado que $52,5 \%$ dos pacientes continuaram necessitando de tratamento medicamentoso, esporádico ou contínuo, após a cirurgia, em decorrência de quadros de bolsites ou disfunções dos reservatórios ileais ${ }^{35}$.

Clinicamente, a bolsite se caracteriza por diarréia aquosa, aumento do número de evacuações, dor abdominal, urgência evacuatória, febre, incontinência, mal-estar geral e, em alguns casos, enterorragia. Muitas vezes pode ser acompanhada 
por manifestações extra-intestinais da RCU. Pode apresentar-se sob forma aguda ou crônica, sendo a primeira a mais comumente observada ${ }^{35}$. Episódios recorrentes são relatados em taxas variáveis, de $24,6^{7}$ a $66 \%^{12}$.

Utilizamos os critérios do PDAI em nosso estudo, pois julgamos adequada a confirmação diagnóstica da bolsite com exame endoscópico, biópsia e análise histopatológica. Já foi observado que em até $25 \%$ dos pacientes com sintomas típicos de bolsite não foi confirmado endoscópica ou histopatologicamente o fenômeno ${ }^{8}$. Deve-se sempre realizar o diagnóstico diferencial com outras entidades, classificadas como inflamatórias (retite residual, doença de Crohn, infecção específica da bolsa) e não-inflamatórias (diminuição da complacência da bolsa, síndrome da bolsa irritável, estenoses, alça eferente longa, esvaziamento diminuído, disfunções do assoalho pélvico ou aderências) $)^{10,36}$.

\subsection{Análise microbiológica}

A resolução ocasional dos quadros de bolsites com o uso de Ciprofloxacina e/ou Metronidazol sugere que elas tenham etiologia microbiana, especialmente de anaeróbios. No entanto, nenhum agente bacteriano específico foi isolado, e os estudos já realizados divergem quanto aos tipos de microrganismos prevalentes ${ }^{16,17,18-21,37}$. Ainda, a maioria dos poucos estudos que avaliaram a flora bacteriana associada à mucosa, através da realização de biópsias, não puderam estabelecer relação causal com qualquer agente específico ${ }^{18,38}$. Apenas um estudo recente, similarmente ao que observamos, demonstrou elevação na contagem de Bacteroides correlacionada ao aumento de infiltrados de monócitos e granulócitos 
na mucosa da bolsa ileal. O mesmo estudo evidenciou elevação na concentração de Clostridium nestes pacientes e um certo efeito protetor exercido pelos Enterococcus, Enterobactérias e Streptococcus ${ }^{39}$. Este tipo de análise com base em fragmentos teciduais elimina o efeito distorcido que pode ser causado pela simples quantificação microbiana de amostras fecais, o que pode refletir apenas a flora transitória das bolsas ileais ${ }^{40}$.

Demonstrou-se que a flora das bolsas ileais reproduz a flora colônica, através da comprovação da atividade da azo e nitroreductase em seus efluentes (própria das bactérias colônicas) $)^{41}$, e com um aumento tanto da relação anaeróbios/aeróbios, como da presença de Bacteroides e Bifidobacteria, além de alterações histopatológicas da mucosa, como atrofia vilosa e hiperplasia das $\operatorname{criptas}^{16,17}$. Um estudo com microscopia eletrônica de varredura realizado em nosso serviço demonstra claramente esta "colonização" do epitélio ileal: a progressão de um epitélio rico em vilosidades e sem criptas, para outro, com achatamento, atrofia, e até desaparecimento das vilosidades, além de fácil visualização das criptas de Lieberkün, à semelhança dos epitélios colônico e retal ${ }^{42}$. A metaplasia colônica, comumente observada nos reservatórios, caracteriza-se pela produção de sulfomucina (colônica) ao invés de sialomucina (produzida no intestino delgado) ${ }^{18}$.

Assim, a escassez de estudos que avaliam a flora associada à mucosa das bolsas ileais restringe o estabelecimento de comparações com nosso estudo; ao mesmo tempo, a frequente "colonização" do epitélio ileal e a similaridade clínica, evolutiva e histopatológica de pacientes com bolsites e retocolite ulcerativa nos permite estabelecer paralelos entre estes dois grupos. 
Estudo conduzido por Smith et $\mathrm{al}^{37}$ caracterizou a flora microbiana de pacientes submetidos a retocolectomia total, assintomáticos, com bolsas ileais por RCU, estomas por RCU e bolsas por PAF. Foi observado, no primeiro grupo, o predomínio de anaeróbios estritos (bactérias redutoras de sulfato, Clostridium perfrigens, Bifidobacteria e Bacteroides); de anaeróbios facultativos (Enterococci, Lactobacilli e coliformes) no segundo grupo; e proporções equivalentes de estritos e facultativos no terceiro.

Atenção especial vem sendo conferida recentemente ao papel das bactérias redutoras de sulfato (BRS) na etiopatogenia das bolsites. As BRS são bactérias próprias da flora colônica normal, e produzem sulfido de hidrogênio $\left(\mathrm{H}_{2} \mathrm{~S}\right)$, um gás altamente tóxico à mucosa das bolsas ileais. No cólon, há um sistema de detoxificação bastante desenvolvido, que rapidamente converte o sulfido em tiossulfato $^{43}$. Em ratos, demonstrou-se que este sistema possui, no íleo, 1/10 da atividade observada no ceco ${ }^{44}$. As BRS foram isoladas das fezes de pacientes com bolsas por RCU, mas não de ileostomias por RCU ou de bolsas por $\mathrm{PAF}^{45}$. Além disso, um estudo posterior revelou que a liberação de $\mathrm{H}_{2} \mathrm{~S}$ foi significativamente maior em pacientes com bolsite, comparativamente aos que nunca a tiveram ou aos que a mantiveram inativa no último ano ${ }^{46}$. As BRS estão aumentadas no cólon de pacientes com RCU, só surgem nas bolsas após o fechamento da ileostomia, utilizam a barreira mucosa como fonte energética, induzem a apoptose dos colonócitos e ulceração mucosa e inibem a oxidação do butirato $^{45}$. Em casos de bolsites crônicas refratárias, torna-se necessária a exclusão de agentes menos comuns, como Clostridium difficile $e^{47}$ e citomegalovírus ${ }^{48}$. 
Os ácidos graxos de cadeia curta, especialmente o butirato, constituem importante combustível para a mucosa colônica, por inibirem a proliferação celular e estimularem a diferenciação celular ${ }^{19}$. Foi verificado também que os organismos produtores de butirato protegeriam a mucosa através da inibição do crescimento dos Bacteroides $^{17}$. Diante destes dados, no entanto, observamos uma contradição, se considerarmos a tendência de "colonização" da mucosa da bolsa ileal com o decorrer dos anos, e que esta "colonização" teoricamente aumentaria a produção de butirato e protegeria a mucosa de danos inflamatórios, o que não é observado na prática.

Em nosso estudo, o aumento da prevalência de Bacteroides sp nos produtos de biópsias de pacientes com bolsites coincide com alguns estudos prévios ${ }^{16}$ que avaliaram amostras fecais. Além disso, já foram observadas concentrações aumentadas de Bacteroides sp no muco coletado de bolsas ileais dois meses após o fechamento das ileostomias, comparativamente ao reto de controles $^{40}$. Habitualmente, em indivíduos sadios, foi demonstrado predomínio estatisticamente significativo de Bacteroides sp não-pigmentado no sigmóide e reto, comparativamente a outros locais do trato digestivo baixo, também através da análise do muco coletado 49 . Assim, além da "colonização" da bolsa ileal em pacientes operados, já comprovada por alterações histopatológicas e por alterações da flora residente, ocorreria uma proliferação ainda maior deste microrganismo em bolsas ileais, e em alguns indivíduos susceptíveis isso poderia desencadear uma sequência de eventos responsáveis pelo surgimento das bolsites.

Mesmo sendo escassos os estudos envolvendo a caracterização da flora associada à mucosa das bolsas ileais e sua possível correlação com as bolsites, alguns 
autores já sugeriram a presença de Bacteroides sp como possível agente etiológico em pacientes com RCU.

Sessenta a $70 \%$ dos pacientes com RCU e $25 \%$ dos pacientes com Doença de Crohn produzem auto-anticorpos citoplasmáticos específicos a uma proteína dos neutrófilos de distribuição perinuclear (pANCA). Duas espécies de proteínas inumorreativas a pANCA foram detectadas em bactérias residentes na mucosa colônica: uma proteína de 100kDa, encontrada em Bacteroides caccae e a Omp C, expressa em $E$. coli $^{50}$. Além disso, já foi observado que a frequência de pANCA em pacientes com bolsite crônica foi significativamente maior que nos pacientes com colite, com bolsa ileal sem inflamação ou com colite e ileostomia ${ }^{22}$.

Outro fator importante a ser considerado na estruturação de uma possível base etiopatogênica das doenças inflamatórias intestinais é a formação de um biofilme junto à mucosa colônica e entérica. O biofilme é uma comunidade de células bacterianas organizada dentro de uma matriz polimérica auto-produzida e aderente a uma superfície ${ }^{51}$. Através da técnica FISH (Hibridização por Fluorescência in situ), que combina a identificação molecular das bactérias com a visualização direta de sua relação com a mucosa, foi observado que Bacteroides sp compõem mais de $60 \%$ do biofilme dos pacientes com doenças inflamatórias intestinais e apenas 30\% em pacientes com colite auto-limitada e menos de $15 \%$ em pacientes com Síndrome do Intestino Irritável $(p<0,001)^{52}$. Além disso, o mesmo estudo demonstrou a persistência de bactérias em pacientes tratados por 5-ASA ou antibióticos, indicando que o biofilme pode sobreviver a substâncias antibacterianas. Este fato corrobora o aumento significativo de Bacteroides sp na mucosa de pacientes com bolsites, 
mesmo sob antibioticoterapia, observado em nosso estudo. Já foi descrita, inclusive, uma resistência a antibióticos relativamente comum por Bacteroides fragilis ${ }^{53}$.

A escassez de trabalhos em humanos nos levou à revisão de estudos experimentais. Alguns deles já visaram elucidar a associação de Bacteroides sp com quadros de retocolite. Demonstrou-se que a colonização por Bacteroides fragilis enterotoxigênico (BFET) em ratos pode desencadear quadro de colite assintomática $(p<0,05)$ ou piorar significativamente o quadro clínico iniciado previamente por um agonista inflamatório, o DSS (sulfato de sódio dextran), comparativamente ao placebo ou à colonização por Bacteroides fragilis não-toxigênico $(p<0,05)^{54}$. O mesmo estudo sugere que o BFET parece iniciar tanto uma resposta inflamatória mucosa, através da secreção de toxinas proinflamatórias, como uma resposta sistêmica, devido ao achado de esplenomegalia nos ratos com colite. Já foi demonstrado que a enterotoxina do Bacteroides fragilis aumenta a permeabilidade mucosa e a internalização epitelial de bactérias entéricas ${ }^{55}$.

Modelos experimentais de colite ulcerativa em porcos demonstraram que a resposta inflamatória pode ser exacerbada por prévia imunização com algumas correntes de Bacteroides vulgatus, através da transferência de células esplênicas de animais imunizados, e posterior alimentação com o mesmo microrganismo, sugerindo um envolvimento do sistema imune mediado por células neste modelo ${ }^{56}$. O mesmo grupo, posteriormente, isolou antígenos da membrana externa bacteriana responsáveis pelo efeito imunológico observado ${ }^{57}$.

A avaliação de amostras teciduais do reto de pacientes com RCU demonstrou elevação na contagem de vários gêneros de bactérias, incluindo Bifidobacterium, Bacteroides, Eubacterium, Clostridium, etc., comparativamente ao grupo controle 
$(p<0,05)$. O mesmo estudo investigou respostas imunológicas séricas contra as bactérias isoladas da mucosa inflamada e observou altos títulos de aglutinação contra Bacteroides vulgatus, Bacteroides fragilis e Clostridium ramosum na maioria dos pacientes com RCU. Além disso, através da avaliação por imunoblotting, foi isolada uma proteína da membrana externa do Bacteroides vulgatus, de 26-kDa (BV43-26), contra a qual a imunorreatividade sérica em pacientes com RCU foi muito maior $(53,8 \%)$ que nos controles $(9,1 \%)^{58}$.

Ainda, foram descritos os toll-like receptors (TLR), que são anticorpos policlonais reguladores-chave no reconhecimento de moléculas associadas a patógenos antimicrobianos. Dois de seus subtipos, o TLR2 e TLR4, estão superexpressos na mucosa de bolsas ileais inflamadas, o que representaria uma hiperresposta às bactérias comensais nestes pacientes ${ }^{59}$.

Foram também comparados e seguidos por seis meses grupos de ratos trangênicos livres de germes com ratos colonizados por bactérias não-patogênicas, pertencentes à microflora intestinal, livre de bactérias patogênicas, vírus e parasitas. Observou-se que apenas os ratos colonizados por Bacteroides sp desenvolveram quadros de colite e gastrite, implicando assim o papel desta flora na patogênese da inflamação intestinal crônica. Além disso, o padrão de citocinas e marcadores bioquímicos observado neste grupo foi similar ao descrito em humanos com doenças inflamatórias intestinais (IL-1 $\alpha$, IL-1 $\beta$, IL-1RA, TNF- $\alpha$ e IL-6) ${ }^{60}$. Isto demonstra fortemente a implicação da flora intestinal normal no desencadeamento de quadros de colite.

Discute-se, inclusive, o mecanismo através do qual a flora intestinal residente deflagaria a resposta inflamatória intestinal. Observou-se que tanto espécies de 
Bifidobacterium como de Bacteroides estimulam a proliferação de clones de células T CD4+TCR $\alpha \beta+$ tanto do sangue periférico, como de amostras teciduais de pacientes com doenças inflamatórias intestinais, e que há reação cruzada entre estes anaeróbios e enterobactérias. Sugere-se, assim, uma hiperresponsividade imune mediada por células $\mathrm{T}$ a antígenos da microflora intestinal ${ }^{61}$. Foi demonstrado, inclusive, em bolsas ileais, que a flora de pacientes com bolsites estimularia uma intensa proliferação de células mononucleares, tanto no sangue periférico $(p=0,012)$, como na lâmina própria ( $p=0,018)$, ao contrário da flora de bolsas sem inflamação. Este efeito foi ainda mais pronunciado quando do estímulo pelo Bacteroides vulgatus, e foi suprimido após administração de metronidazol ${ }^{62}$.

Recente estudo envolvendo 19 pacientes, com bolsites e com bolsas ileais saudáveis (por RCU ou PAF), demonstrou, ao contrário do observado em nossa análise, um predomínio de Bacteroides justamente no grupo de bolsas ileais saudáveis por PAF comparativamente ao grupo com bolsites, após análise por DNA fecal. Ao mesmo tempo, houve predomínio tanto nas fezes como na mucosa de Lactobacillus e Streptococcus no mesmo grupo. Houve, ainda, predomínio de Clostridium e Eubacterium na análise fecal dos pacientes com bolsites ${ }^{63}$.

Como já observado por alguns autores, a microflora intestinal pode ser também afetada por uma série de fatores externos, independentemente das conformações anatômicas dos reservatórios ileais e da estase fecal ${ }^{27}$. A dieta e a ingestão de probióticos, nem sempre valorizados ou considerados como "tratamento" pelos pacientes, podem reduzir as bactérias patogênicas independentemente do uso de antibióticos, minimizando a agressão inflamatória e os sintomas. 
O mecanismo exato através do qual os Bacteroides $s p$ e outros anaeróbios estritos desencadeiam alterações mucosas ainda não está claro. Diante das contradições observadas, destacamos a importância de novos estudos para caracterizar o impacto e o papel destas e outras bactérias na patogênese das bolsites. Como já publicado, parece não haver valor preditivo no isolamento destas bactérias previamente ao procedimento operatório para a determinação de prognóstico para o desenvolvimento de bolsites ${ }^{40}$. No entanto, a caracterização destes microrganismos associado à determinação de processos fisiopatológicos, bioquímicos, inflamatórios e/ou imunológicos que gerem as lesões características das doenças inflamatórias intestinais, em especial as bolsites, pode proporcionar perspectivas de tratamento e qualidade de vida aos muitos pacientes que sofrem com esta entidade clínica. A nãoresponsividade completa a antibióticos, inclusive, amplia possibilidades a outras opções terapêuticas, como a terapia biológica e os probióticos, a partir do momento em que tais processos fisiopatológicos estiverem adequadamente elucidados. 


\subsection{Análise histopatológica}

Estudos prévios correlacionaram a presença de metaplasia colônica à vigência de inflamação da bolsa ileal, sugerindo que a atrofia vilosa e a hiperplasia das criptas representem predominantemente uma resposta reparativa à confecção dos reservatórios ileais. Além disso, a ausência de metaplasia em bolsas por PAF sugeriria que tal transformação da mucosa não seria atribuível apenas a respostas adaptativas à conformação anatômica, mas sim à doença de base ${ }^{64}$.

Nosso estudo, no entanto, não confirmou a associação entre a metaplasia colônica e a presença de bolsites. Além disso, houve correlação da atrofia mucosa com o tempo de seguimento pós-operatório, independentemente da presença de bolsites, ao contrário de estudo Apel et al., que sugeriu que a atrofia vilosa não aumentaria com o tempo de seguimento ${ }^{65}$. Assim, não só a estase fecal e a proliferação bacteriana estariam envolvidas no processo adaptativo da mucosa ileal, conforme observações prévias ${ }^{66}$.

Estudo de Trovato et $\mathrm{al}^{67}$ avaliou bolsas ileais através de endomicroscopia a laser confocal in vivo e por análise histopatológica, e obteve incidências de metaplasia colônica de $67,7 \%$ e $83,3 \%$, respectivamente, e atrofia vilosa em $83,3 \%$ nas duas análises. Em nosso estudo, tanto a metaplasia colônica, como a atrofia vilosa foram observadas em $36,6 \%$ dos pacientes. Em ambos os estudos, não houve detecção de displasias.

Mesmo que o processo de transformação neoplásica não seja o foco de nosso estudo, consideramos relevante a completa caracterização histopatológica das bolsas ileais, incluindo a abordagem de alterações pré-neoplásicas pois, apesar de raro, o 
adenocarcinoma do reservatório ileal já foi descrito e, inclusive, caracterizado como conseqüente à bolsite atrófica crônica. Supõe-se que a inflamação persistente da bolsa ileal possa sofrer degeneração maligna similarmente ao que ocorre no cólon inflamado. Há relatos de desenvolvimento de adenocarcinomas sobre mucosa ileal acometida por intensa inflamação crônica e atrofia unicamente, sem história prévia de neoplasias ou outros fatores de risco $^{68-70}$.

Não houve detecção de displasias ou neoplasias nas mucosas das bolsas ileais de nossos pacientes, assim como observado na maioria dos estudos, onde a presença de tais alterações foi rara ou ausente ${ }^{71-75}$. Kariv et $\mathrm{al}^{76}$ avaliaram 3203 pacientes com bolsa ileal e revelaram incidência de $0,72 \%$ de displasias e $0,36 \%$ de adenocarcinomas e consideraram como fatores de risco apenas os diagnósticos préoperatórios de displasias ou adenocarcinomas do cólon ou reto.

Assim, de modo geral, não se justificaria vigilância endoscópica precoce pósoperatória. No entanto, seria interessante que, em bolsas de maior tempo pósoperatório, fossem realizados exames endoscópicos de rotina visando a uma busca ativa de atrofia mucosa, mesmo em pacientes assintomáticos, devido à associação da atrofia com a seqüência bolsite atrófica - displasia - adenocarcinoma ${ }^{68,77,78}$. 


\section{CONCLUSÕES}


3.1. Concentrações elevadas de Bacteroides $s p$ na flora associada à mucosa parecem aumentar o risco de desenvolvimento de bolsites;

3.2. O aumento na concentração de anaeróbios na bolsa ileal sugere maior risco de bolsites;

3.3. O grau de atrofia da mucosa, a presença de metaplasia colônica, o grau de inflamação aguda ou crônica não parecem constituir fatores de risco para o desenvolvimento de bolsites;

3.4. Quanto maior o tempo de seguimento pós-operatório, maior o grau de atrofia da mucosa. 
8.REFERÊNCIAS 
1. Habr-Gama A, Teixeira MG. Tratamento cirúrgico da Retocolite Ulcerativa / Proctocolectomia restauradora com bolsa ileal. In: Habr-Gama A (ed). Doença Inflamatória Intestinal, Clínica Brasileira de Cirurgia, Ano III, Volume III. Atheneu, Brasil, 1997.

2. Rauh SM, Schoetz Jr DJ, Roberts PL, Murray JJ, Coller JA, Veidenheimer MC. Pouchitis - is it a wastebasket diagnosis? Dis Colon Rectum. 1991;34:685-9.

3. Stahlberg D, Gullberg K, Liljeqvist L, Hellers G, Löfberg R. Pouchitis following pelvic pouch operation for ulcerative colitis - Incidence, cumulative risk and risk factors. Dis Colon Rectum. 1996;39:1012-18.

4. Lohmuller JL, Pemberton JH, Dozois RR, Ilstrup DM, van Heerden J. Pouchitis and extraintestinal manifestations of inflammatory bowel disease after ileal pouch-anal anastomosis. Ann Surg. 1990;211:622-9.

5. Svaninger G, Nordgren $\mathrm{S}$, Öresland $\mathrm{T}$, Hultén $\mathrm{L}$. Incidence and characteristics of pouchitis in the Koch continent ileostomy and the pelvic pouch. Scand J Gastroenterol. 1993;28:695-700.

6. Simchuk EJ, Thirlby RC. Risk factors and true incidence of pouchitis in patients after ileal pouch-anal anastomosis. World J Surg. 2000;24:851-6.

7. Fazio VW, Ziv Y, Church JM, Oakley JR, Lavery IC, Milson JW, et al. Ileal pouch-anal anastomosis complications and function in 1005 patients. Ann Surg. 1995;222:120-7.

8. Shen B, Achkar JP, Lashner BA, Ormsby AH, Remzi FH, Bevins CL, et al. Endoscopic and histologic evaluation together with symptom assessment are required to diagnose pouchitis. Gastroenterology. 2001;121:261-7. 
9. Hata K, Watanabe M, Shinozaki M, Nagawa H. Patients with extraintestinal manifestations have a higher risk of developing pouchitis in ulcerative colitis: multivariate analysis. Scand J Gastroenterol. 2003;10:1055-8.

10. Shen B, Fazio VW, Remzi FH, Delaney CP, Bennett AE, Achkar JP, et al. Comprehensive evaluation of inflammatory and noninflammatory sequelae of ileal pouch-anal anastomoses. Am J Gastroenterol. 2005;100:93-101.

11. Aisenberg J, Legnani PE, Nilubol N, Cobrin GM, Ellozy SH, Hegazi RAF, et al. Are pANCA, ASCA or cytokine gene polymorphisms associated with pouchitis? Long-term follow-up in 102 ulcerative colitis patients. Am J Gastroenterol. 2004;99:432-41.

12. Hurst RD, Molinari M, Chung P, Rubin M, Michelassi F. Prospective study of the incidence, timing, and treatment of pouchitis in 104 consecutive patients after restorative proctocolectomy. Arch Surg. 1996;131:497-500.

13. Dozois RR, Kelly KA, Welling DR, Gordon H, Beart RW, Wolff BG, et al. Ileal pouch-anal anastomosis: comparison of results in familial adenomatous polyposis and chronic ulcerative colitis. Ann Surg. 1989;210:268-73.

14. Teixeira WGJ, Silva JH, Teixeira MG, Almeida MG, Calache JE, Habr-Gama A. Pouchitis: extracolonic manifestation of ulcerative colitis? Rev Hosp Clin Fac Med S Paulo. 1999;54:155-8.

15. Stallmach A, Moser C, Hero-Gross R, Muller-Molaian I, Ecker KW, Feifel $\mathrm{G}$, et al. Pattern of mucosal adaptation in acute and chronic pouchitis. Dis Colon Rectum. 1999;42:1311-7. 
16. Kmiot WA, Youngs D, Tudor R, Thompson H, Keighley MRB. Mucosal morphology, cell proliferation and faecal bacteriology in acute pouchitis. $\mathrm{Br} J$ Surg. 1993;80:1445-9.

17. Nasmyth DG, Godwin PGR, Dixon MF, Williams NS, Johnston D. Ileal ecology after pouch-anal anastomosis or ileostomy. Gastroenterology. $1989 ; 96: 817-24$.

18. Kuisma J, Mentula S, Luukkonen P, Jarvinen H, Kahri A, Farkkila M. Factors associated with ileal mucosal morphology and inflammation in patients with ileal pouch-anal anastomosis for ulcerative colitis. Dis Colon Rectum. 2003;46:1476-83.

19. Ruseler-van Embden JG, Schouten WR, van Lieshout LM. Pouchitis: result of microbial imbalance? Gut. 1994;35:658-64.

20. Sandborn WJ, Tremaine WJ, Batts KP, Pemberton JH, Rossi SS, Hofmann AF, et al. Fecal bile acids, short-chain fatty acids, and bacteria after ileal pouch-anal anastomosis do not differ in patients with pouchitis. Dig Dis Sci. 1995;40:1474-83.

21. O’ Connell PR, Rankin DR, Weiland LH, Kelly KA. Enteric bacteriology, absorption, morphology and emptying after ileal pouch-anal anastomosis. $\mathrm{Br}$ J Surg. 1986;73:909-14.

22. Sandborn WJ, Landers CJ, Tremaine WJ, Targan SR. Antineutrophil cytoplasmic antibody correlates with chronic pouchitis after ileal pouch-anal anastomosis. Am J Gastroenterol. 1995;90:740-7. 
23. Utsunomiya J, Iwana I, Imajo M, Matsuo S, Sawai S, Yaegashi K, et al. Total colectomy mucosal proctectomy and ileoanal anastomosis. Dis Colon Rectum. 1980;23:459.

24. Sandborn WJ, Tremaine WJ, Batts KP, Pemberton JH, Phillips S. Pouchitis after ileal pouch-anal anastomosis: a pouchitis disease activity index. Mayo Clin Proc. 1994;69:409-15.

25. Cowan ST, Steel KJ. Manual for the identification of medical bacteria. 2. ed. New York, Cambridge University Press, 1974.

26. Holdeman LV, Cato EP, Moore WEC. Anaerobic Laboratory Manual. 4. ed. Blacksburg, Virginia Polytechnics, Institute and State University, 1977.

27. Sutter VL, Citron DM, Finegold SM. Wadsmorth Anaerobic Bacteriology Manual. 3. ed. St. Louis, C. V. Mosby, 1980.

28. Parks AG, Nicholls RJ. Proctocolectomy without ileostomy for ulcerative colitis. Br Med J. 1978; 2:85-88.

29. Brooke BN. The outcome of surgery for ulcerative colitis. Lancet. 1956;ii:532-6.

30. Fonkalsrud EW, Ament ME. Endorectal mucosal resection without proctocolectomy as an adjunct to abdominoperineal resection for non malignant conditions: clinical experience with five patients. Am Surg. $1978 ; 188: 245-8$.

31. Nicholls RJ, Lubowski DZ. Restorative proctocolectomy: the four loop W reservoir. Br J Surg. 1987;74:564-6.

32. Kiss DR, Vilarino TC, Almeida MG. Tratamento cirúrgico da RCUI e da polipose cólica familial pela proctocolectomia com anastomose de 
reservatório ileal em $\mathrm{J}$ ao canal anal, com e sem mucosectomia retal. Rev Bras Coloproct. 1991;11:131.

33. Habr-Gama A, Teixeira MG, Brunetti Netto C, Sousa Jr AHS, Alves PRA, Vieira MJF, et al. Proctocolectomia total com anastomose ileoanal e bolsa ileal em J para tratamento de retocolite ulcerativ. Rev Bras Coloproct. 1993;13(3):100-5.

34. Habr-Gama A, Araújo SEA. Retocolectomia total e qualidade de vida. Arq Gastroenterol. 1996;33:45-7.

35. Teixeira MG, Ponte ACA, Sousa M, Almeida MG, Silva Filho E, Calache JE, et al. Short- and long-term outcomes of ileal pouch-anal anastomosis for ulcerative colitis. Rev Hosp Clin Fac Med S Paulo. 2003;58:193-8.

36. Pardi DS, Sandborn WJ. Systematic review: the management of pouchitis. Aliment Pharmacol Ther. 2006;23:1087-96.

37. Smith FM, Coffey JC, Kell MR, O' Sullivan M, Redmond HP, Kirwan WO. A characterization of anaerobic colonization and associated mucosal adaptations in the undiseased ileal pouch. Colorectal Dis. 2005;7:563-70.

38. Onderdonk AB, Dvorak AM, Cisneros RL, Mc Leod RS, Antionoli D, Silen W, et al. Microbiologic Assessment of Tissue Biopsy Samples from Ileal Pouch Patients. J Clin Microbiol. 1992;30:312-7.

39. Scarpa M, Grillo A, Faggian D, Ruffolo C, Bonello E, D'Incà R, et al. Relationship between mucosa-associated microbiota and inflammatory parameters in the ileal pouch after restorative proctocolectomy for ulcerative colitis. Surgery. 2011;150(1):56-67. 
40. Almeida MG, Kiss DR, Zilberstein B, Quintanilha AG, Teixeira MG, HabrGama A. Intestinal mucosa-associated microflora in ulcerative colitis patients before and after restorative proctocolectomy with an ileoanal pouch. Dis Colon Rectum. 2008;51:1113-19.

41. Rafii F, Ruseler-Van Embden JGH, Asad YF. Azoreductase and nitroreductase activity of bacteria in feces from patients with an ileal reservoir. Dig Dis Sci. 1997;42:133-6.

42. Kiss DR, Habr-Gama A, Freymüller E, Smith RL, Pinotti HW. Microscopia eletrônica de varredura da superfície epitelial do íleo em reservatórios ileais pélvicos e após anastomose ileorretal. Rev Bras Colo-Proct. 1994;14:81-8.

43. Levitt MD, Furne J, Springfield J, Suarez F, DeMaster E. Detoxification of hydrogen sulfide and methanethiol in the cecal mucosa. J Clin Invest. 1999;104:1107-14.

44. Furne JK, Springfield JR, Koenig T, DeMaster E, Levitt MD. Oxidation of hydrogen sulfide and methanethiol to thiosulfate by rat tissues: a specialized function of the colonic mucosa. Biochem Pharmacol. 2001;62:255-9.

45. Duffy M, O’ Mahony L, Coffey JC, Collins JK, Shanahan F, Redmond HP, et al. Sulfate-reducing bacteria colonize pouches formed for ulcerative colitis but not for familial adenomatous polyposis. Dis Colon Rectum. 2002;45:3848.

46. Ohge H, Furne JK, Springfield J, Rothenberger DA, Madoff RD, Levitt MD. Association between fecal hydrogen sulfide production and pouchitis. Dis Colon Rectum. 2005;48:469-75. 
47. Shen B, Goldblum JR, Hull TL, Remzi FH, Bennett AE, Fazio VW. Clostridium-difficile-associated pouchitis. Dig Dis Sci. 2006;51:2361-4.

48. Moonka D, Furth EE, MacDermott RP, Liechtenstein GR. Pouchitis associated with primary cytomegalovirus infection. Am J Gastroenterol. 1998;93:264-6.

49. Quintanilha AG, Zilberstein B, Santos MAA, Pajecki D, Moura EGH, Alves PRA, et al. A novel sampling method for the investigation of gut microbiota. World J Gastroenterol. 2007 ;13:3990-5.

50. Cohavy O, Bruckr D, Gordon LK, Misra R, Wei B, Eggena ME, et al. Colonic bacteria Express na ulcerative colitis pANCA-related protein epitope. Infect Immun. 2000;68:1542-8.

51. Costerton JW, Stewart PS, Greenberg EP. Bacterial biofilms: a common cause of persistent infections. Science. 1999;284:1318-22.

52. Swidsinski A, Weber J, Loening-Baucke V, Hale LP, Lochs H. Spatial organization and composition of the mucosal flora in patients with inflammatory bowel disease. J Clin Microbiol. 2005;43:3380-9.

53. Snydman DR, Jacobus NV, Mc Dermott LA, Ruthazer R, Golan Y, Goldstein EJC, et al. National survey on the susceptibility of Bacteroides fragilis group: report and analysis of trends in the United States from 1997 to 2004. Antimicrob Agents Chemother. 2007;51:1649-55.

54. Rabizadeh S, Rhee KJ, Shaoguang W, Huso D, Gan CM, Golub JE, et al. Enterotoxigenic Bacteroides fragilis: A potential instigator of colitis. Inflamm Bowel Dis. 2007;13:1475-83. 
55. Wells CL, van de Westerlo MA, Jechorek RP, Feltis BA, Wilkins TD, Erlandsen SL. Bacteroides fragilis enterotoxin modulates epithelial permeability and bacterial internalization by HT-29 enterocytes. Gastroenterology. 1996;110:1429-37.

56. Onderdonk AB, Steeves RM, Cisneros RL, Bronson RT. Adoptive transfer of immune enhancement of experimental ulcerative colitis. Infect Immun. 1984;46:64-7.

57. Breeling JL, Onderdonk AB, Cisneros RL, Kasper DL. Bacteroides vulgates outer membrane antigens associated with carragenan-induced colitis in guinea pigs. Infect Immun. 1988;56:1754-9.

58. Matsuda H, Fujiyama Y, Andoh A, Ushijima T, Kajinami T, Bamba T. Characterization of antibody responses against rectal mucosa-associated bacterial flora in patients with ulcerative colitis. $J$ Gastroenterol Hepatol.2000;15:61-8.

59. Toiyama Y, Araki T, Yoshiyama S, Hiro J-I, Miki C, Kusunoki M. The expression patterns of toll-like receptors in the ileal pouch mucosa of postoperative ulcerative colitis patients. Surg today. 2006;36:287-90.

60. Rath HC, Herfarth H, Ikeda JS, Grenther WB, Hamm TE, Balish E, et al. Normal luminal bacteria, especially Bacteroides species, mediate chronic colitis, gastritis, and arthritis in HLA-B27-Human 2 microglobulin transgenic rats. J Clin Invest. 1996;98:945-53.

61. Duchmann R, May E, Heike M, Knolle P, Neurath M, Buschenfelde K-HM. T-cell specificity and cross reactivity towards enterobacteria, Bacteroides, 
Bifidobacterium, and antigens from resident intestinal flora in humans. Gut. $1999 ; 44: 812-8$

62. Bell AJG, Nicholls RJ, Forbes A, Ellis HJ, Ciclitira PJ. Human Lymphocyte stimulation with pouchitis flora is greater than with flora from a healthy pouch but is suppressed by metronidazole. Gut. 2004;53:1801-5.

63. Zella GC, Hait EJ, Glavan T, Gevers D, Ward DV, Kitts CL, et al. Distinct microbiome in pouchitis compared to healthy pouches in Ulcerative Colitis and Familial Adenomatous Polyposis. Inflamm Bowel Dis. 2011;17(5):1092100.

64. Fruin AB, El-Zammer O, Stucchi AF, O’Brien M, Becker JM. Colonic metaplasia in the ileal pouch is associated with inflammation and is not the result of long-term adaptation. J Gastrointest Surg. 2003;7:246-54.

65. Apel R, Choen Z, Andrews CW Jr, McLeod R, Steinhart H, Odze R. Prospective evaluation of early morphological changes in pelvic ileal pouches. Gastroenterology. 1994;107:435-43.

66. De Silva HJ, Millard PR, Kettlewell M, Mortensen NJ, Prince C, Jewell DP. Mucosal characteristics of pelvic ileal pouches. Gut. 1991;32:61-5.

67. Trovato C, Sonzogni A, Fiori G, Ravizza D, Tamayo D, Botti F, et al. Confocal laser endomicroscopy for the detection of mucosal changes in ileal pouch after restorative proctocolectomy. Dig Liver Dis. 2009;41(8):578-85.

68. Knupper N, Straub E, Terpe HJ, Vestweber KH. Adenocarcinoma of the ileoanal pouch for ulcerative colitis--a complication of severe chronic atrophic pouchitis? Int J Colorectal Dis. 2006;21:478-82. 
69. Heuschen UA, Heuschen G, Autschbach F, Allemeyer EH, Herfarth C. Adenocarcinoma in the ileal pouch: late risk of cancer after restorative proctocolectomy. Int J Colorectal Dis. 2001;16(2):126-30.

70. Hassan C, Zullo A, Speziale G, Stella F, Lorenzetti R, Morini S. Adenocarcinoma of the ileoanal pouch anastomosis: an emerging complication? Int J Colorectal Dis. 2003;18(3):276-8.

71. Nilubol N, Scherl E, Bub DS, Gorfine SR, Marion J, Harris MT, et al. Mucosal dysplasia in ileal pelvic pouches after restorative proctocolectomy. Dis Colon Rectum. 2007;50:825-31.

72. Herline AJ, Meisinger LL, Rusin LC, Roberts PL, Murray JJ, Coller JA, et al. Is routine pouch surveillance for dysplasia indicated for ileoanal pouches? Dis Colon Rectum. 2003;46:156-9.

73. Hultén L, Willén R, Nilsson O, Safarani N, Haboubi N. Mucosal assessment for dysplasia and câncer in the ileal pouch mucosa in patients operated on for ulcerative colitis- a 30-year follow-up study. Dis Colon Rectum. 2002;45:448-52.

74. Thompson-Fawcett MW, Marcus V, Redston M, Cohen Z, McLeod RS. Risk of dysplasia in long-term ileal pouches and pouches with chronic pouchitis. Gastroenterology. 2001;121:275-81.

75. Ettore GM, Pescatori M, Panis Y, Nemeth J, Crescenzi A, Valleur P. Mucosal changes in ileal pouches after restorative proctocolectomy for ulcerative and Crohn's colitis. Dis Colon Rectum. 2000;43:1743-8.

76. Kariv R, Remzi FH, Lian L, Bennett AE, Kiran RP, Kariv Y, et al. Preoperative colorectal neoplasia increases risk for pouch neoplasia in 
patients with restorative proctocolectomy. Gastroenterology. 2010;139(3):806-12.

77. Stein RB, Lichtenstein GR. Complications after ileal pouch-anal anastomosis. Semin Gastrointest Dis. 2000;11:2-9.

78. Gullberg K, Lindforss U, Zetterquist H, Stålberg D, Reinholt FP, Veress B, et al. Cancer risk assessment in long-standing pouchitis. DNA aberrations are rare in transformed neoplastic pelvic pouch mucosa. Int J Colorectal Dis. $2002 ; 17: 92-7$ 
APÊNDICES 


\section{Relação de prontuários do Hospital das Clínicas da FMUSP utilizados em nosso estudo:}

3008743c, 2338581c, 2358270a, 2498916d, 3110908g, 2401385i, 3003269c, 13627562a, 3332955c, 3277164b, 2845270d, 2989977f, 2598331i, 3262800e, 2826189c, 2446007e, 2640142j, 3319168f, 3205057c, 3203373j, 3366478i, 2435343g, 3024267j, 3386144k, 13446721b, 3324011g, 6003785a, 3066602e, 3386976a 2758776h, 13518792c, 2672137b, 2858031b, 3255224j, 13593009f, 2911597j, 3213247b, 3022243h, 2796514k, 13536084h, 3103476j 


\section{Termo de aprovação do projeto de pesquisa pela CAPPesq:}

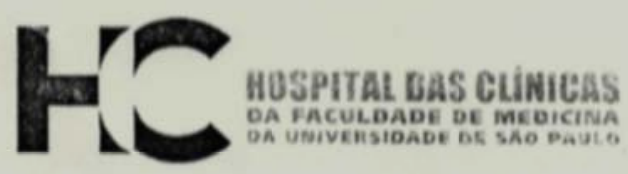

\section{APROVAÇÃO}

A Comissão de Ética para Análise de Projetos de Pesquisa CAPPesq da Diretoria Clínica do Hospital das Clínicas e da Faculdade de Medicina da Universidade de São Paulo, em sessão de 02/04/2008, APROVOU o Protocolo de Pesquisa $n^{\circ} 1162 / 07$, infifulado: "AVALIAÇÃO DO PERFIL MICROBIOLÓGICO FECAL E DOS FATORES DE RISCO RELACIONADOS AO DESENVOLVIMENTO DE BOLSITES EM PACIENTES SUBMETIDOS A RETOCOLECTOMIA TOTAL RESTAURADORA COM BOLSA ILEAL POR RETOCOLITE ULCERATIVA" apresentado pelo Departamento de GASTROENTEROLOGIA, inclusive o Termo de Consentimento Livre e Esclarecido.

Cabe ao pesquisador elaborar e apresentar à CAPPesq, os relatorios parciais e final sobre a pesquisa (Resoluçăo do Conselho Nacional de Saúde $n^{\circ} 196$, de 10/10/1996, inciso (X.2, letra "c").

Pesquisador (a) Responsável: Dra. Magaly Gemio Teixeira

Pesquisador (a) Executante: Dra. Roberta Thiery de Godoy Arashiro

CAPPesq, 07 de Abril de 2008

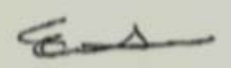

Prof. Dr. Eduardo Massad Presidente da Comissão de Ética para Análise de Projełos de Pesquisa

Comiss do de Etica para Analise de Projetos de Pesquisa do HCFMUSP e da FMUSP Diretoria Clínica do Hospital das Clinicas da Faculdade de Medicina da Universidade de SAo Paulo Rua Ovidio Pires de Campos, 255, $5^{\circ}$ andar - CEP 05403010 - SAo Paulo SP Fone: 01130696442 Fax 01130696492 e-mail: cappesqChenet.usp.br / secretariacapposq2 Ghenot. usp.br 